\title{
LOCAL ORIGINS IMPART CONSERVED BONE TYPE-RELATED DIFFERENCES IN HUMAN OSTEOBLAST BEHAVIOUR
}

\author{
M. Shah ${ }^{1 *}$, V. Gburcik ${ }^{1}$, P. Reilly ${ }^{2}$, R.A. Sankey², R.J. Emery ${ }^{2}$, C.E. Clarkin ${ }^{3}$ and A.A Pitsillides ${ }^{1}$ \\ ${ }^{1}$ Department of Comparative Biomedical Sciences, Royal Veterinary College, London, NW1 0TU, UK \\ 2.Department of Surgery and Cancer, Faculty of Medicine, Imperial College London, SW7 1AZ, UK \\ ${ }^{3 .}$ Centre for Biological Sciences, University of Southampton, Southampton, SO16 6YD. UK
}

\begin{abstract}
Osteogenic behaviour of osteoblasts from trabecular, cortical and subchondral bone were examined to determine any bone type-selective differences in samples from both osteoarthritic (OA) and osteoporotic (OP) patients. Cell growth, differentiation; alkaline phosphatase (TNAP) mRNA and activity, Runt-related transcription factor-2 (RUNX2), SP7-transcription factor (SP7), bone sialoprotein-II $(B S P-I I)$, osteocalcin/bone gammacarboxyglutamate $(B G L A P)$, osteoprotegerin $(\mathrm{OPG}$, TNFRSF 11B), receptor activator of nuclear factor- $\kappa \beta$ ligand (RANKL, TNFSF11) mRNA levels and proangiogenic vascular endothelial growth factor-A $(V E G F-A)$ mRNA and protein release were assessed in osteoblasts from paired humeral head samples from age-matched, human OA/OP $(n=5 / 4)$ patients. Initial outgrowth and increase in cell number were significantly faster $(p<0.01)$ in subchondral and cortical than trabecular osteoblasts, in OA and OP, and this bone type-related differences were conserved despite consistently faster growth in OA. RUNX2/SP7 levels and TNAP mRNA and protein activity were, however, greater in trabecular than subchondral and cortical osteoblasts in OA and OP. BSP-II levels were significantly greater in trabecular and lowest in cortical osteoblasts in both OA and OP. In contrast, BGLAP levels showed divergent bone type-selective behaviour; highest in osteoblasts from subchondral origins in $\mathrm{OA}$ and trabecular origins in OP. We found virtually identical bone type-related differences, however, in TNFRSF11B:TNFSF 11 in OA and $\mathrm{OP}$, consistent with greater potential for paracrine effects on osteoclasts in trabecular osteoblasts. Subchondral osteoblasts (OA) exhibited highest $V E G F-A$ mRNA levels and release. Our data indicate that human osteoblasts in trabecular, subchondral and cortical bone have inherent, programmed diversity, with specific bone type-related differences in growth, differentiation and pro-angiogenic potential in vitro.
\end{abstract}

Keywords: In vitro, human osteoblasts, shoulder arthroplasty, vasculature, subchondral, trabecular, cortical, osteogenic differentiation.

*Address for correspondence:

Mittal Shah, PhD

Department of Comparative Biomedical Science

Royal Veterinary College, London, NW1 0TU, UK

Telephone number: +44 (0)2074685248

Email:mshah@rvc.ac.uk

\section{Introduction}

Osteoblasts isolated from diverse anatomical sites have been used to study bone cell behaviour in vitro. Thus, calvarial- and long bone-derived cells from rodents are very common model systems. Cells with disparate origins, such as trabecular and cortical bone, are also used somewhat interchangeably, to inform understanding of skeletal biology. Although all bone exhibits some highly conserved factors in its development, remodelling and repair, it is also apparent that the response to many in vivo challenges is not always identical in trabecular, cortical and subchondral bones types (Lavigne et al., 2005; Simon et al., 2008; Wade-Gueye et al., 2010). Differences in osteoblasts derived from long bone and calvarial sites, including distinct transcriptional signatures, have been described in vitro (Akintoye et al., 2006; Rawlinson et al., 2009). Solchaga and colleagues have described the difference in osteogenic potential in cells from the same bone, however originating from different anatomical locations such as marrow and periosteum in rabbit tibia (Solchaga et al., 1998). Furthermore, within the same bone structure, osteoblasts display differential gene transcriptions depending on their anatomical location (Candeliere et al., 2001). Cell preparations from trabecular, cortical and subchondral bone types have not yet, however, been extensively compared in parallel assays and it remains possible that bone cell behaviour in these diverse bone types may be underpinned by the origins and performance of local osteoblasts. It is also possible that sampling and assessment of cells from one particular bone type might obscure or conceal differences in osteoblasts, when comparing disease states.

The trabecular bone is located mainly in the metaphysis and extremities of long bones and comprises of structures and architectures that differ markedly from those found in the cortical or subchondral bone. Despite constituting a relatively small fraction of total bone volume, organisational alignment of bone structures in this trabecular compartment normally produces robust load-bearing and much of the total bone surface area for remodelling (Lanyon, 1984). Trabecular bone is also more porous and less dense than cortical bone, and supplies most of the exchangeable pool of calcium. It is thought that this large surface area contributes to a higher metabolic remodelling activity compared to cortical bone (Aerssens et al., 1997). These comparisons illustrate the differing functions of bone that exist even within a single anatomical location in these structurally diverse compartments, and it is clear that they also differ in how they are affected by 
metabolic challenges, vascular influences or diseases, such as osteoarthritis (OA) and osteoporosis (OP).

These distinct types of bone compartment are affected differently in OA and OP, and both diseases are also strongly influenced by age and metabolism, and by mechanical load-related and inheritable genetic factors (Aerssens et al., 1997; Bultink and Lems, 2013; Lories and Luyten, 2012; Richards et al., 2012). OA progression involves cartilage degradation, synovium and tendon inflammation, osteophyte formation and a characteristic thickening of the subchondral bone plate (Li et al., 1999). This subchondral bone thickening is thought to have mechanical origins and may also be associated with emerging genetics, such as GDF5 (encoding growth differentiation factor 5) polymorphisms that have been linked with OA(Dodd et al., 2012). The diminished bone mass and microarchitecture deterioration in OP is likely linked to dysfunctional mechanoadaptive responses or, for example, variants of multiple genes associated with bone mineral density such as $V D R$ (encoding vitamin D receptor), PTH1R (encoding PTH receptor 1), RANK-RANKL-OPG, oestrogen and Wnt signalling pathways (Estrada et al., 2012; Kanis and Johnell, 2011). The relationship between OA and OP is debated (Dequeker et al., 1975; Jiang et al., 2008; Pervaiz et al., 2013; Verstraeten et al., 1991). It is clear, nevertheless, that bone in the trabecular compartment in OP patients has lower strength and is of poor quality, whereas sclerotic, stiffer bone is found in the subchondral trabecular compartment in OA. These increases in stiffness of OA bone are not however necessarily correlated with strength. Indeed, Ding et al. (Ding et al., 2002) reported that the subchondral thickness is significantly increased in early OA but that it remains weaker than bone in healthy patients. For these reasons, comparisons between trabecular-, cortical- and subchondral-derived osteoblasts in distinct OA and OP patient groups will likely reveal any conserved bone type-selective behaviours of osteoblasts isolated from these different compartments. Conversely, any disease related differences that are conserved in all bone types in either OA or OP osteoblasts might provide novel insight into the underpinning disease mechanisms.

Most studies using isolated primary human osteoblasts have not regarded the possibility that their site of origin from within a bone may influence behaviour. We have explored the hypotheses that osteoblasts derived from subchondral, cortical and trabecular bone types (from OA patients) exhibit differing osteogenic potential, and that these regional differences will persist even in samples from OP patients where osteogenic potential of isolated osteoblasts will be diminished. Using osteoblasts derived from these different bone types within a singular skeletal element, namely the head of the human humerus from OA and OP patients undergoing shoulder replacement surgery, our studies find that osteoblasts from OP patients exhibit a lesser osteogenic potential. Consistent with our hypothesis, we also find, however, a preservation of divergent growth dynamics, differentiation potential and modified proangiogenic activity in osteoblasts derived from trabecular, cortical and subchondral bone types. Divergent osteogenic and angiogenic potentials of bone cells from the different bone types could influence the design and selection of future orthopaedic implants in the human shoulder, and perhaps more broadly, such that they achieve improved osseo-integration and thus limit complications, such as prosthetic loosening, gleno-humeral instability and periprosthetic fracture (Bohsali et al., 2006).

\section{Materials and Methods}

\section{Patients and sample preparation}

Paired subchondral, trabecular and cortical bone samples were obtained intra-operatively from nine consecutive female patients during open total shoulder replacements or hemiarthroplasties. There were five female OA (mean age, 74 years; range 72-81 years) and four female OP patients (mean age, 80 years; range $73-86$ years) selected by NHS clinical guidelines. None of these OP patients were suffering from vitamin D deficiency or renal disease and none were receiving cortisone treatment. All OP patients had received bisphosphonate treatment and dietary calcium supplements. Our supplementary studies used the rare opportunity to make comparison with paired subchondral, trabecular and cortical bone samples from one 'normal' female patient (30 years of age, undergoing humeral metaphyseal metastasis resection) without osteoarthritis or osteoporosis (Royal National Orthopaedic Hospital). Informed consent was obtained preoperatively from each patient in accordance with the approval from the Ethical Committees of Imperial NHS trust and Royal National Orthopaedic Hospital Biobank regulations in compliance with the United Kingdom Human Tissues Act 2004. Bone samples were collected under aseptic conditions in separate containers and transported from the operating theatre in sterile phosphate-buffered saline (PBS).

\section{Preparation of explants and subchondral, trabecular and cortical bone primary osteoblasts}

Separate explant cultures were prepared from subchondral (Hilal et al., 1998), trabecular (Taylor et al., 2014) and cortical bone samples taken from fixed anatomical locations from each patient during surgery (Fig.1). Subchondral bone was prepared by removing overlaying cartilage from the resected humeral head using a scalpel, followed by removal of trabecular bone from beneath using bone-cutters and rongeurs. This produces multiple $\sim 2 \mathrm{~mm}$ thick subchondral bone plate fragments, from which trabecular remnants were removed using a scalpel and scissors, that were subsequently dissected into $\sim 1 \mathrm{~mm}^{3}$ pieces. Trabecular bone from the humeral metaphysis was cut into $\sim 1 \mathrm{~mm}^{3}$ chips and cleared of superficial marrow and fat by extensive agitation in PBS. Cortical bone, obtained by rongeur from the proximal humerus, was cleared of adherent marrow by scalpel, cut into $\sim 1 \mathrm{~mm}^{3}$ chips using a bone cutter and washed by extensive PBS agitation. In all three cases, dissected segments were then placed in sterile PBS.

These bone chips were used to establish explant cultures (multiple $\sim 1 \mathrm{~mm}^{3}$ bone chips $(\sim 20-30)$ in each flask (typically 2 flasks) for each bone type from each patient) to facilitate osteoblast outgrowth as previously described (Beresford et al., 1993; Clarkin et al., 2008a; Clarkin et 


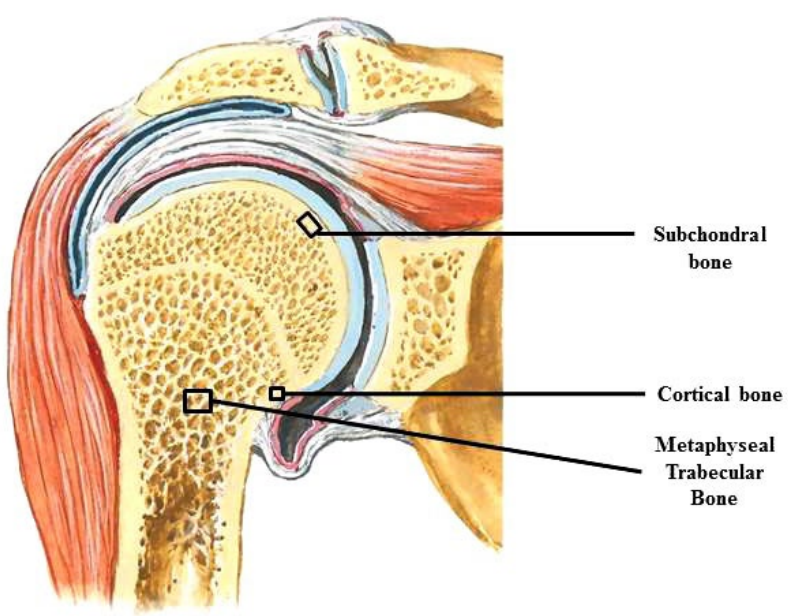

Fig. 1. Cross-sectional schematic illustration of a Human gleno-humeral joint depicting different anatomical bone types. The different bone types from which the samples were obtained for the current study are highlighted in the black boxes. Figure purchased from Netter Images (Elsevier: www.netterimages.com).

al., 2008b; Couchourel et al., 2009; Dillon et al., 2012; Gallagher et al., 1996; Grigoriadis et al., 1988; Hilal et al., 1998; Jagodzinski et al., 2004; Kwan Tat et al., 2010; Lajeunesse, 2002; Oshina et al., 2007; Rawlinson et al., 1995; Rawlinson et al., 2009; Siggelkow et al., 1999; Simon et al., 2008; Taylor et al., 2014; Wong et al., 1990). Briefly, to restrict the number of non-bone contaminating cells the bone segments were washed with PBS containing $10 \%$ antibiotic-antimycotic (AB/AM) (Invitrogen, Paisley, UK)) six times by vortexing and transferred into appropriately labelled $7 \mathrm{~mL}$ bijous tubes containing $0.25 \%$ trypsin- trypsin/ethylenediaminetetraacetic acid (EDTA) (Invitrogen, Paisley, UK) and placed in a shaking water bath at $37^{\circ} \mathrm{C}$ for $10 \mathrm{~min}$. After a brief wash in PBS, the segments were incubated with $1 \%$ type II collagenase from Clostridium histolyticum (Sigma Aldrich, Dorset, UK) for $30 \mathrm{~min}$ in a shaking water bath at $37^{\circ} \mathrm{C}$ to remove contaminating surface marrow cells. The bone chips were washed three times in sterile PBS containing $10 \%$ antibiotic-antimycotics, then placed into $75 \mathrm{~mm}^{2}$ tissue culture flasks (NUNC, UK) with Dulbecco's minimal essential medium (DMEM; without phenol red, containing sodium pyruvate and $1 \mathrm{~g} / \mathrm{L}$ d-glucose; (Invitrogen, Paisley, United Kingdom)) supplemented with $10 \%$ heatinactivated foetal bovine serum (Invitrogen, Paisley, United Kingdom), $2 \mathrm{mM}$ L-glutamine, $100 \mathrm{U} / \mathrm{mL}$ of penicillin, $100 \mathrm{mg} / \mathrm{mL}$ of streptomycin and $0.25 \mu \mathrm{g} / \mathrm{mL}$ Amphotericin) and maintained in a humidified incubator at $37^{\circ} \mathrm{C}$ for $6-8$ weeks to allow cellular outgrowth with media changes every week. Cells were observed growing out the explant after 7 days. Explant cultures (for each bone type in each patient) were prepared for subsequent analysis (see below) and cell outgrowth (\% confluence) was monitored daily using a grid system placed under each culture flask to assess the number of days taken to produce $85 \%$ cell coverage of the total grid surface (expressed as $1 /$ number of days taken). Having reached $85 \%$ confluence, each of these cultures were first washed with PBS and the remaining bone chips discarded, then Accutase ${ }^{\mathrm{TM}}$ (Invitrogen, Paisley, UK)-digested, replicate flasks (typically 2) pooled and subseeded in a range of formats described below, with media changes performed every 2 days, for subsequent analyses in which only passage 1 cells were used. In the case of the single set of rare normal samples, explants of each bone type were re-cultured three times following confluence to establish new replicate independent cultures (e.g. E1, E2, E3) as described elsewhere (Gartland et al., 2012).

\section{Cell number and viability}

Prior studies have shown four-fold increase in human osteoblast numbers between 1-10 days of culture (Siggelkow et al., 1999). Crystal violet viability test was employed based on the inability of dead cells to remain adherent to cell culture plastic (McDonald et al., 2013; Sohaskey et al., 2010; Vora et al., 2010). Briefly, cells derived from subchondral, trabecular and cortical bone explants were sub-seeded at 2,000 cells/well into 48-well plates in basal media and maintained for 10 days before assessment of cell number and viability (triplicates for each bone type from each patient). After 10 days, cells were washed three times with PBS and fixed in $4 \%$ para-formaldehyde (PFA) (Sigma Aldrich, Dorset, UK). Monolayers of attached cells were then stained with $0.1 \%$ crystal violet dye in distilled $\mathrm{H}_{2} \mathrm{O}$ for $30 \mathrm{~min}$ for DNA. Excess dye was removed and cells thoroughly washed and bound stain subsequently eluted from cells using $10 \%$ acetic acid. The quantity of eluted stain was measured at $595 \mathrm{~nm}$ using a 96-well microtitre plate reader. A standard curve was prepared with known serial dilutions of stained cells from which and the total numbers of DAPI (Invitrogen, Paisley, United Kingdom) positive cells in the experiments were extrapolated.

\section{Alkaline phosphatase activity (TNAP) assay and staining}

Osteoblasts derived from subchondral, trabecular, and cortical human bone were sub-seeded at 20,000 cells/well in 24-well plates in triplicate per patient and maintained in basal medium with half media changes on alternate days until confluent (typically 15 days for subchondral and cortical, and 21 days for trabecular osteoblasts). Cells were then incubated in either basal medium or basal medium supplemented with $\beta$-glycerophosphate $(2 \mathrm{mM})$, ascorbate2-phosphate $(50 \mu \mathrm{g} / \mathrm{mL})$ and a synthetic glucocorticoid (10 nM dexamethasone, Sigma, Dorset, UK (referred to as osteogenic medium, + OM herein) for 36 days prior to assessment of TNAP activity (triplicates for each bone type from each patient).

Total TNAP activity was assessed in cell lysates from individual wells by a method modified from that described by Lowry et al. and Shah et al. (Lowry et al., 1954; Shah et al., 2010). Briefly, cells were rinsed three times with PBS, digested with $0.1 \%$ Triton X-100, scraped off the plate and the cell suspension sonicated (Ultrasonic disintegrator, MSE laboratories, Butte, MT). Briefly, enzyme activity in half of total volume of these cell lysates was measured in assay buffer containing $0.1 \mathrm{M}$ diethanolamine, $1 \mathrm{mM}$ 
$\mathrm{MgCl}_{2}$ and $2 \mathrm{mM}$ p-nitrophenylphosphate (Sigma Aldrich, Dorset, UK) pH 10.5 added to cell homogenates. A standard curve was prepared with p-nitrophenol solutions. Incubation of standards and samples was performed at $37^{\circ} \mathrm{C}$ for $5 \mathrm{~min}$ and the reaction stopped by adding $0.3 \mathrm{M}$ $\mathrm{NaOH}$. Reaction mixtures were transferred into 96-well plates and absorbance measured at $410 \mathrm{~nm}$. A fraction of the lysate was also used to measure protein content with the bicinchoninic acid (BCA) assay reagent (Pierce, Rockford, IL) and the relative TNAP activity was defined as nanomoles of p-nitrophenol phosphate hydrolysed $/ \mathrm{min} /$ $\mathrm{mg}$ of total protein. TNAP activity was also visualised by histochemical staining in additional wells using naphthol AS-TR (Sigma Aldrich, Dorset, UK) as a substrate and Fast blue to produce a coloured precipitate, as previously described (Shah et al., 2010). Stained wells were imaged using a high-resolution flatbed scanner.

\section{RNA isolation}

Human osteoblasts from each of the patient-matched bone types were sub-seeded at 20,000 cells/well in basal medium in 24-well plates in triplicate and maintained until confluent (see above), at which point total RNA was collected for gene expression analysis (in triplicate). For TNAP mRNA expression analysis, total RNA was collected $24 \mathrm{~h} ; 7 \mathrm{~d}$ and $14 \mathrm{~d}$ post confluence. Medium was removed and the monolayers were agitated and lysed with $200 \mu \mathrm{L}$ Qiazol (Qiagen, UK) using a cell scraper. The lysates were transferred into clean microcentrifuge tubes and homogenised by passing through a $23 \mathrm{~g}$ sterile needle and $200 \mu \mathrm{L}$ of $100 \%$ ethanol added. The homogenates were then vortexed 3 times for $5 \mathrm{~s}$. Total cellular RNA was isolated from the homogenates using the Direct-Zol ${ }^{\mathrm{TM}}$ miniprep kit (Zymoresearch, Cedarlanelabs, Canada) according to the manufacturer's instructions. RNA integrity was established by gel electrophoresis and RNA purity by nanodrop spectroscopy (NanoDrop ${ }^{\circledR}$ ND-1000 UV-Vis Spectrophotometer (Thermo Scientific, UK)). Acceptable samples displayed two clear ribosomal bands (indicating no degradation had occurred during isolation), 260/280 ratios $>2.0$ and 260/230 ratios $>1.8$ (Hildyard and Wells, 2014; Nolan et al., 2006).

\section{cDNA synthesis and Real Time Quantitative PCR}

Reverse transcription was performed on triplicate $200 \mathrm{ng}$ samples of total RNA ( $20 \mu \mathrm{L}$ reaction volume) using a high-capacity RNA-to-complementary DNA (cDNA) kit (Applied Biosystems (Invitrogen, Paisley, UK)) run at $37^{\circ} \mathrm{C}$ for $60 \mathrm{~min}$ and at $85^{\circ} \mathrm{C}$ for $5 \mathrm{~min}$ (Poulet et al., 2012). To detect messenger RNA (mRNA) transcripts, primers (designed using Primer3 Plus (Galea et al., 2013; Rozen and Skaletsky, 2000) (see Table 1 for details)) were premixed with SYBR Green JumpStart Taq ReadyMix (Sigma Aldrich, Dorset, UK), and $10 \mu \mathrm{L}$ aliquots were applied to 384-well optical plates (white hard-shell thin-walled) Bio-Rad Biorad, Herts, UK), The 1:4 diluted cDNA were applied in triplicate in $2 \mu \mathrm{L}$ aliquots such that each plate consisted matching subchondral, trabecular and cortical bone samples from all patients (in triplicate). Thermal cycling conditions were as follows: $10 \mathrm{~min}$ at $95^{\circ} \mathrm{C}$, with 40 cycles of $15 \mathrm{~s}$ at $95^{\circ} \mathrm{C}, 30 \mathrm{~s}$ at $60^{\circ} \mathrm{C}$, and $20 \mathrm{~s}$ at $72^{\circ} \mathrm{C}$, on a Bio-Rad CFX384 Real-Time System. Dilution series were

Table 1. List of Primers used for qPCR. (a) (Atkins et al., 2011) and ${ }^{\text {(b) }}$ (Kiselak et al., 2010).

\begin{tabular}{|c|c|c|c|c|}
\hline NCBI Reference & Details & Gene ID & & Primer Sequence 5' - 3' \\
\hline \multirow{2}{*}{ NM_001024630.3 } & \multirow{2}{*}{$\begin{array}{l}\text { Runt related transcription } \\
\text { factor } 2 \text { (RUNX2) }\end{array}$} & \multirow{2}{*}{$R U N X-2$} & Forward & GGAGTGGACGAGGCAAGAGTTT \\
\hline & & & Reverse & AGCTTCTGTCTGTGCCTTCTGG \\
\hline \multirow{2}{*}{ NM_001173467.1 } & \multirow{2}{*}{ Osterix } & \multirow{2}{*}{$S P 7$} & Forward & TGGACATGACACACCCCTATG \\
\hline & & & Reverse & CCACCACCTAGCCAGTTGC \\
\hline \multirow{2}{*}{ NM_004967.3 } & \multirow{2}{*}{ Bone Sialoprotein-II } & \multirow{2}{*}{ BSP-II } & Forward & GAACCTCGTGGGGACAATTAC \\
\hline & & & Reverse & CATCATAGCCATCGTAGCCTTG \\
\hline \multirow{2}{*}{ NM_199173.4 } & \multirow{2}{*}{ Osteocalcin } & \multirow{2}{*}{$B G L A P$} & Forward & CTTTGTGTCCAAGCAGGAGG \\
\hline & & & Reverse & CTGAAAGCCGATGTGGTCAG \\
\hline \multirow{2}{*}{ NM_001025366.2 } & \multirow{2}{*}{$\begin{array}{l}\text { Vascular endothelial growth } \\
\text { factor-A }\end{array}$} & \multirow{2}{*}{$V E G F-A$} & Forward & CACTGAGGAGTCCAACATACC \\
\hline & & & Reverse & CTGCATTCACATTTGTTGTC \\
\hline \multirow{2}{*}{ NM_003701.3 } & \multirow{2}{*}{$\begin{array}{l}\text { Receptor activator of } \\
\text { nuclear factor kappa-B } \\
\text { ligand (RANKL) }\end{array}$} & \multirow{2}{*}{ TNFSF11 } & Forward & CCAGGTTGTCTGCAGCGT \\
\hline & & & Reverse & TGCAGTGAGTGCCATCTTCT \\
\hline \multirow{2}{*}{ NM_002546.3 } & \multirow{2}{*}{ Osteoprotegerin (OPG) } & \multirow{2}{*}{ TNFRSF11B } & Forward & GCAACACAGCTCACAAGAAC \\
\hline & & & Reverse & GAAGGTGAGGTTAGCATGTCC \\
\hline \multirow{2}{*}{ NM_000478.4 } & \multirow{2}{*}{ Alkaline phosphatase } & \multirow{2}{*}{$T N A P^{(a)}$} & Forward & TGCTCCCACGCGCTTGTGCCTGGA \\
\hline & & & Reverse & CTGGCACTAAGGAGTTAGTAAG \\
\hline \multirow{2}{*}{ NR_003286.2 } & \multirow{2}{*}{ 18s rRNA } & \multirow{2}{*}{$18 s r R N A^{(b)}$} & Forward & GGCCCTGTAATTGGAATGAGTC \\
\hline & & & Reverse & CCAAGATCCAACTACGAGCTT \\
\hline \multirow{2}{*}{ NM_004048.2 } & \multirow{2}{*}{$\beta_{2}$-Microglobulin } & \multirow{2}{*}{$B 2 M$} & Forward & AGCAAGGACTGGTCTTTCTATCTC \\
\hline & & & Reverse & CATGTCTCGATCCCACTTAACTATC \\
\hline
\end{tabular}


used to establish that residual cDNA synthesis reagents did not impair PCR efficiency and each run consisted of melt curve analysis and template-free controls to confirm specific, single product amplification. All primer pairs produced single amplicons and reactions were of similar efficiency (95-100\%), as established by standard dilution curve and analysis. Target gene quantification was achieved using the $2{ }^{\Delta \Delta C T}$ method described by Livak et al. (Livak and Schmittgen, 2001) adapted from Pfafll (Pfaffl, 2001) relative to the ratio of $\beta_{2}$-microglobulin (B2M): $18 s$ rRNA $(18 s)$ which were chosen against a panel of housekeeping genes; $\beta$-actin, cyclophillinA and GAPDH using GeNorm software to determine the most stable housekeeping gene (http://medgen.ugent.be/ jvdesomp/genorm/) by making pairwise comparison to rank candidate genes by summed individual variation, discarding the most variant before repeating pairwise analysis to identify $\beta_{2}$-microglobulin and $18 s$ rRNA genes with minimum respective variation (Bustin et al., 2009; Hildyard and Wells, 2014; Nolan et al., 2006).

\section{Quantification of Vascular Endothelial Growth Factor- $A_{165}$ protein release}

Human osteoblasts from each bone type were seeded in 24 well plates (passage 1) at a density of 20,000 cells/well (triplicates per patient) were maintained in basal media until confluent. At confluence, conditioned media were collected (and monolayers lysed for RNA collection, as indicated above). VEGF ${ }_{165}$ concentration was measured by enzyme linked immunosorbent assay using the $\mathrm{VEGF}_{165}$ antibody pair kit (Novex, Invitrogen) according to manufacturer's instructions. In order to maximise yield of data from these cells, VEGF-A ${ }_{165}$ concentration in osteoblast-conditioned medium was normalised to total RNA content measured by nanodrop spectroscopy (Clarkin et al., 2011); RNA was also used in qPCR analyses.

\section{Statistical Analysis}

Triplicate cultures were evaluated within each end point assay for statistical analysis. Therefore, in each case triplicate technical replicates for each endpoint assay were pooled and averaged to eliminate pseudo empowerment of data before statistical testing. Respective data from each patient were treated as independent samples and comparisons between osteoblasts from each bone type within each patient group made using Friedman test since the data violated Gaussian distribution (visual inspection of histograms). Post hoc Dunn's multiple comparison tests were employed for multiple comparisons. Unpaired comparisons between patient groups (OA vs. OP), for osteoblasts from each bone type, were performed using Mann-Whitney $U$ test since the data also violated normality rules and were unpaired. $p$ values of less than 0.05 were considered significant. In addition, principal components analysis (PCA) (Poulet et al., 2014; Ringner, 2008), a dimension reduction technique, was used to summarise 16 correlated measurements (corresponding to all individual end-point targets measured) into a few uncorrelated principal components (PC) across both patient groups and bone types. A linear mixed effects model was used to assess osteoblast differences between bone types and between patient groups while accounting for repeated measures from the same patient, and Fisher's least significant difference was adopted for post-hoc comparison. PCA and linear mixed model analyses were carried out using IBMSPSS version 20. All other statistical tests were carried out using Prism Graphpad version 6.0f for Mac, (GraphPad Software, La Jolla California USA, www.graphpad.com).

\section{Results}

\section{Osteoblasts from subchondral and cortical bone types proliferate more rapidly than those derived from trabecular bone}

Following collagenase digestion, bone chips were devoid of adherent marrow, and cells emerged from explants within 10-14 days of culture. The number of days taken for such cell outgrowth to reach $85 \%$ confluence was recorded and revealed markedly different rates of outgrowth in samples from different bone types (Fig. 2a), with subchondral and cortical bone osteoblasts from OA patients showing similar growth, which significantly exceeded rates from trabecular bone by $\sim 10 \%(p<0.01)$ and $\sim 12 \%(p<0.01)$, respectively (Fig. 2a). A tendency for such superior growth was also evident in osteoblasts from OP patients, where subchondral and cortical bone osteoblasts significantly exceeded growth seen in trabecular osteoblasts only more markedly (by $63 \%, p<0.01 ; 70 \%, p<0.01$, respectively (Fig. 2a)); outgrowth from subchondral and cortical bone did not differ significantly. These data show that bone type-related differences in rate of growth are retained, despite markedly divergent $(p<0.01)$ rates in OP and OA samples. Similar bone type-related differences in cell outgrowth rates, albeit $50 \%$ faster, were also apparent in cells derived from a normal patient (Fig. 9a).

In order to validate these relationships and to control for any bulk cellularity differences between explants, osteoblasts derived from each bone type were seeded at 2,000 cells/well and cell numbers measured after 10 days. This confirmed growth was similar in cortical and subchondral bone osteoblasts and that both exceeded growth of trabecular-derived cells by $25 \%(p<0.01)$ and $43 \%(p<0.01)$ in OA, and by $180 \%(p<0.01)$ and $175 \%$ $(p<0.01)$ in OP patients (Fig. 2b). These bone type-related differences in growth rate were preserved, even though osteoblasts in all three types of bone from OA patients showed significantly faster growth compared to OP patients (by $57 \%, 75 \%$ and $86 \%$ in subchondral, trabecular and cortical bone types ( $p \leq 0.05,0.001$ and 0.01 ), respectively; Fig. 2b). Similar bone type-related trends were found in osteoblasts in the bone samples from the normal patient (Fig. 9b).

\section{$R U N X 2$ and $S P 7 \mathrm{mRNA}$ levels are greater in osteoblasts from trabecular than subchondral and cortical bone types}

The different growth patterns in cells derived from distinct bone types, led us to also examine basal osteogenic gene expression by qPCR. We found that RUNX2 mRNA, the early osteoblastic marker was significantly elevated in osteoblasts from trabecular compared to subchondral and 


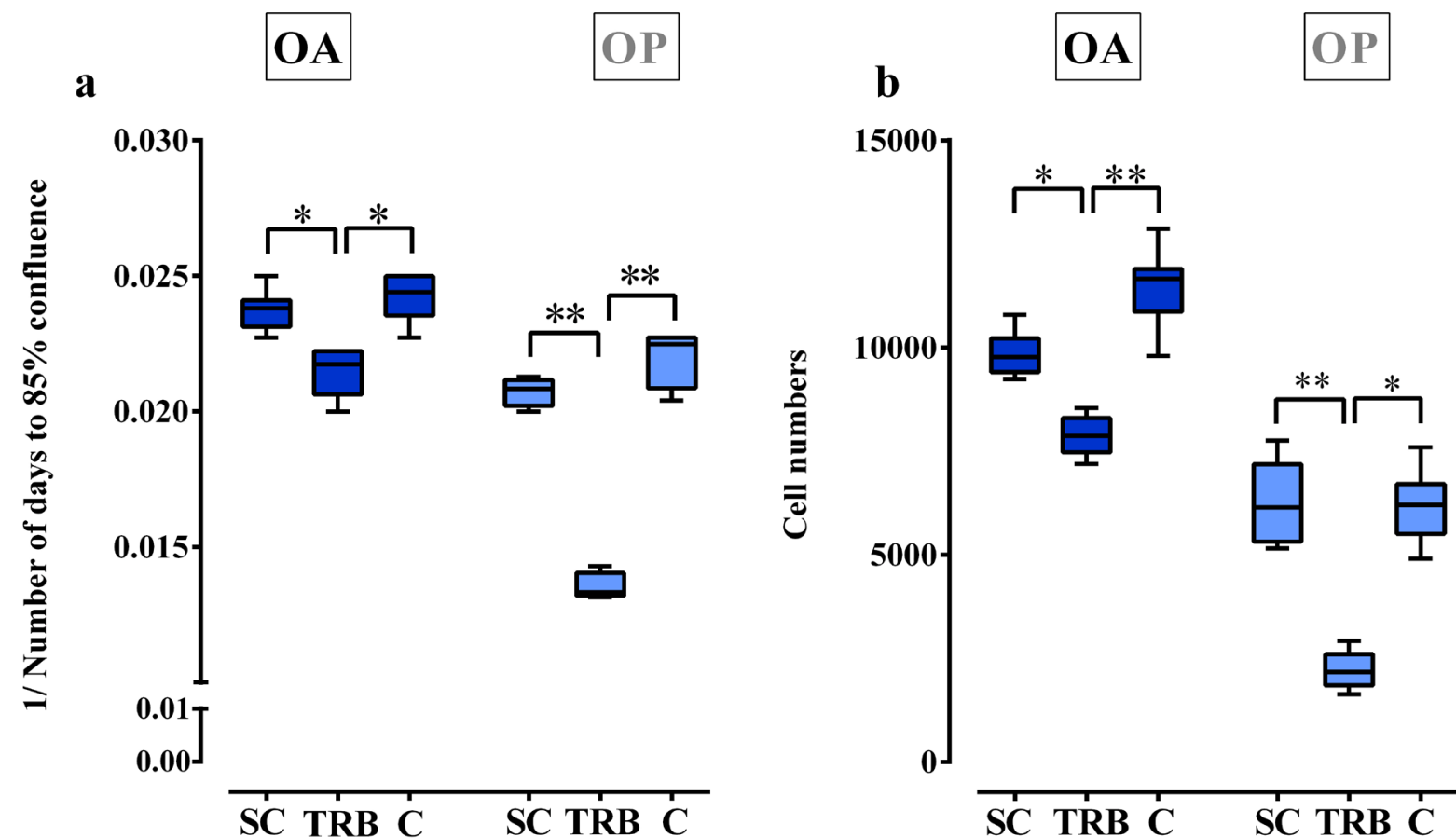

Fig. 2. Human osteoblasts from subchondral (SC), trabecular (TRB) and cortical (C) bone types form OA ( $n=5$ donors) (dark blue boxes) and OP ( $n=4$ donors) (light blue boxes) exhibit modified growth characteristics. (a) Rate of OB growth from SC, TRB and C types of bone explant (to $85 \%$ confluence). (b): OB cell growth from SC, TRB and $\mathrm{C}$ bone types over 10 days measured by crystal violet staining and DAPI nuclear counting. Results are expressed as the mean and $95 \%$ CI (Confidence Intervals). * ** or *** indicates $p$-values less than $0.05,0.01$ or 0.001 respectively compared between osteoblast types. Comparisons between OA and OP for each osteoblast type resulted in $p$-values less than 0.01 .

cortical bone types obtained from both OA (by $43 \%$, $p<0.01$ and $72 \%, p<0.001$ respectively) and OP patients (by $41 \%, p<0.01$ and $83 \%, p<0.001$, respectively) (Fig. $3 \mathbf{a}, \mathbf{b})$. These studies also showed that RUNX2 mRNA levels in subchondral-derived osteoblasts were greater than in osteoblasts from cortical bone from both OA (by $41 \%$, $p<0.01$ ) and OP patients (by $32 \%, p<0.01$ ).

Examination of mRNA levels of SP7, a RUNX2 downstream target, also showed greater expression in trabecular- than in subchondral- $(30 \%, p<0.001)$ and cortical-derived $(67 \%, p<0.001)$ osteoblasts from OA patients (Fig. 3c). Osteoblasts from these different bone types also showed similar, albeit more marked differences when taken from OP patients (50\% and $83 \%$ greater in trabecular osteoblasts compared to cortical and subchondral osteoblasts) (Fig. 3d). OP osteoblasts exhibited lesser $R U N X-2$ and $S P-7$ expression in all osteoblasts compared to OA osteoblasts $(p<0.01)$. These data illustrate that osteoblasts from both OA and OP show conserved, statistically divergent RUNX2 and SP7 mRNA levels in different bone types, and that the ratio of $R U N X 2: S P 7$ were not significantly different in osteoblasts of the different bone types from each. Preliminary data from osteoblasts from normal bone exhibited similar bone type-related differences in RUNX2 and SP7 mRNA expression levels (Fig. 9c,d); exceeded those found in OA and OP samples.

\section{TNAP activity is enriched in trabecular human osteoblasts}

TNAP activity is a marker used to evaluate osteogenic activity. The divergent bone type-related RUNX2 and $S P 7$ mRNA expression prompted an evaluation of TNAP activity in cells from each of the three bone types under basal, otherwise unstimulated (Fig. 4a,c) and osteogenic conditions (Fig. 4b,d). This showed that osteoblasts from trabecular bone type expressed greater TNAP activity under basal conditions $(21 \%, p<0.05$; and $52 \%$, $p<0.01)$ compared to subchondral and cortical types from OA patients. In OP patients, trabecular osteoblasts again showed greater TNAP activity compared to other bone types $(30 \%$, not significant and $66 \%, p<0.01$, respectively. TNAP activity in osteoblasts from each bone type in from OA always exceeded OP samples $(p<0.01)$.

Bone type-related differential basal TNAP activities led us to examine differences under basal and osteogenically stimulated conditions. These data showed increases in TNAP activity in osteoblasts from all bone types in both $\mathrm{OA}$ and $\mathrm{OP}$ patients, with more marked increases in osteoblasts from subchondral and trabecular bone types. These increases did not, however, mask the more marked differences in TNAP activity in osteoblasts from each of the three bone types, with those from trabecular origins retaining the highest and those from cortical origins lowest TNAP activity in both OA and OP groups. Induced 
$\mathbf{a}$

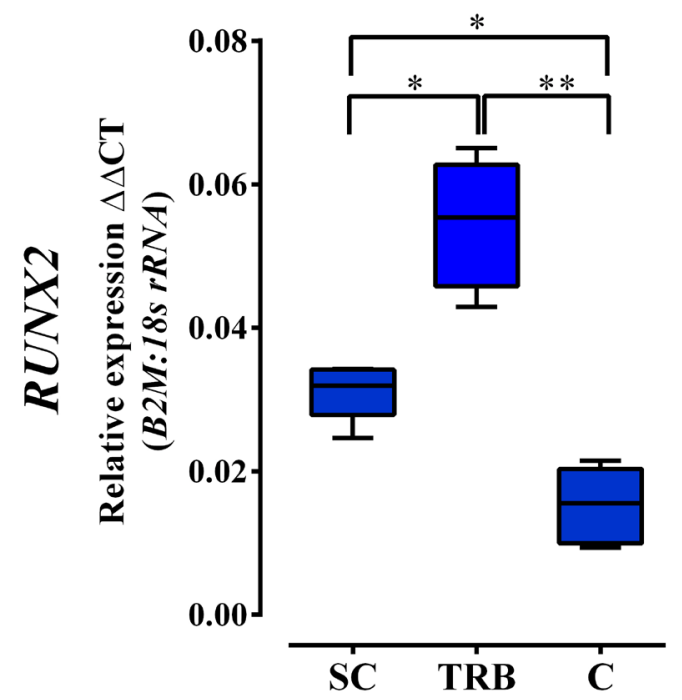

OA

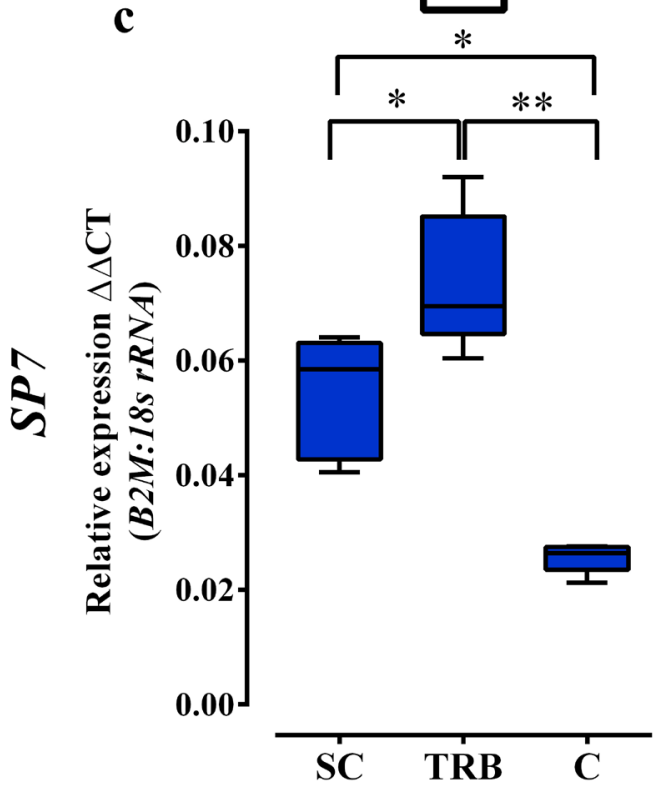

b

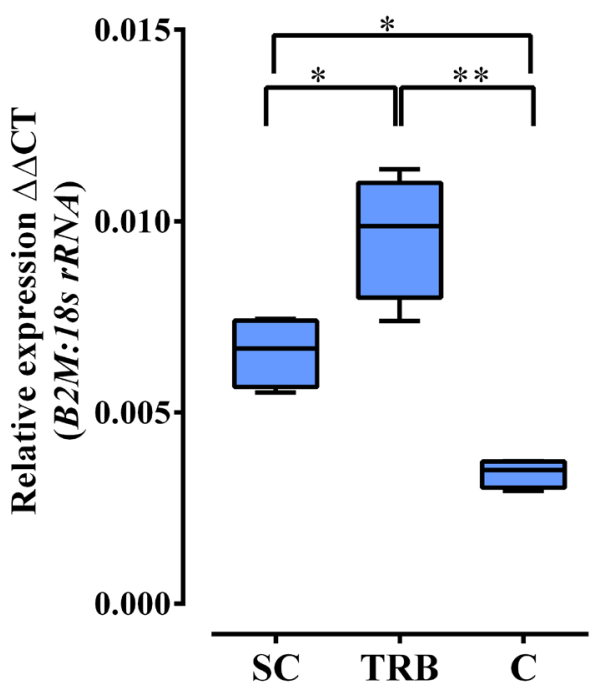

d

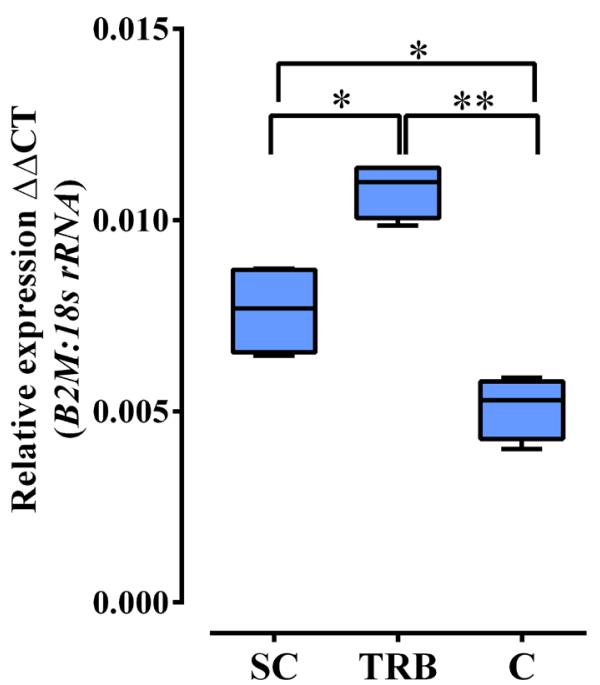

Fig. 3. Osteogenic gene expression in subchondral (SC), trabecular (TRB) and cortical (C) osteoblasts derived from OA ( $n=5$ donors) (dark blue boxes) and OP ( $n=4$ donors) (light blue boxes). RUNX2 (a, b) and $S P 7$ (c, d) osteogenic mRNA expression levels measured by qPCR. Results are expressed as relative mean and $95 \%$ CI. * and ** indicates $p$-values less than 0.05 and 0.01 respectively compared between osteoblast types. Comparisons between OA and OP for each osteoblast type resulted in $p$-values less than 0.01 .

differentiation did, however, mask the differences apparent between subchondral and trabecular bone types. We also measured ALP mRNA levels in cells from each bone type at a range of time-points, post-confluence which revealed greatest TNAP mRNA levels in trabecular and lowest levels in cortical bone osteoblasts, in both OP and OA patients (Table 2). They also show that TNAP mRNA levels do not change significantly from $24 \mathrm{~h}$ to 7 and 14 days post-confluence. Comparing osteoblasts from each bone type showed that TNAP mRNA expression levels were significantly lower in cells from OP compared to OA patients $(p<0.01)$. Data from osteoblasts derived from the single 'normal' patient also exhibited these bone type-related differences in ALP activity under both basal and osteogenically stimulated conditions (Fig. 9e,f). 
Table 2. TNAP mRNA expression over $24 \mathrm{~h}, 7 \mathrm{~d}$ and $14 \mathrm{~d}$ in subchondral (SC), trabecular (TRB) and cortical (C) osteoblasts derived from OA ( $n=5$ donors) and OP ( $n=4$ donors) measured by qPCR. Results are expressed as relative mean \pm SEM. ${ }^{\text {a b }}$ indicates $p$-values less than 0.05 when $\mathrm{SC}$ and $\mathrm{C}$ compared to TRB respectively. Comparisons between $\mathrm{SC}$ and $\mathrm{C}$ are labelled with ${ }^{\mathrm{c}}$ indicating $p<0.05$. Comparisons between $\mathrm{OA}$ and $\mathrm{OP}$ for each osteoblast type resulted in $p$-values less than 0.01 .

\begin{tabular}{|c|c|c|c|}
\hline OA & $24 \mathrm{~h}$ & 7 days & 14 days \\
\hline SC & $\mathbf{0 . 0 3 5 5 9} \pm 0.001412$ & $\mathbf{0 . 0 4 0 8 3} \pm 0.0013$ & $\mathbf{0 . 0 3 6 8 4} \pm 0.0015$ \\
\hline TRB & $\mathbf{0 . 0 5 6 0 6}^{\mathbf{a}, \mathbf{b}} \pm 0.004206$ & $\mathbf{0 . 0 5 9 7 8}^{\mathbf{a}, \mathbf{b}} \pm 0.0035$ & $\mathbf{0 . 0 5 8 0 2}^{\mathbf{a}, \mathbf{b}} \pm 0.0044$ \\
\hline C & $\mathbf{0 . 0 2 0 0 9}^{\mathbf{c}} \pm 0.00243$ & $\mathbf{0 . 0 2 3}^{\mathbf{c}} \pm 0.0028$ & $\mathbf{0 . 0 2 0 8}^{\mathbf{c}} \pm 0.0025$ \\
\hline OP & $24 \mathrm{~h}$ & 7 days & 14 days \\
\hline SC & $\mathbf{0 . 0 2 2 7 9} \pm 0.00113$ & $\mathbf{0 . 0 2 2 3 3} \pm 0.0017$ & $\mathbf{0 . 0 2 1 3 1} \pm 0.0008$ \\
\hline TRB & $\mathbf{0 . 0 3 2 3}^{\mathbf{a}, \mathbf{b}} \pm 0.000796$ & $\mathbf{0 . 0 3 1 9 1}^{\mathbf{a}, \mathbf{b}} \pm 0.03191$ & $\mathbf{0 . 0 3 2 8 4}^{\mathbf{a}, \mathbf{b}} \pm 0.0013$ \\
\hline $\mathbf{C}$ & $\mathbf{0 . 0 1 2 2 1}^{\mathbf{c}} \pm 0.000782$ & $\mathbf{0 . 0 1 4 1 3}^{\mathbf{c}} \pm 0.0009$ & $\mathbf{0 . 0 1 6 2 3}^{\mathbf{c}} \pm 0.0027$ \\
\hline
\end{tabular}
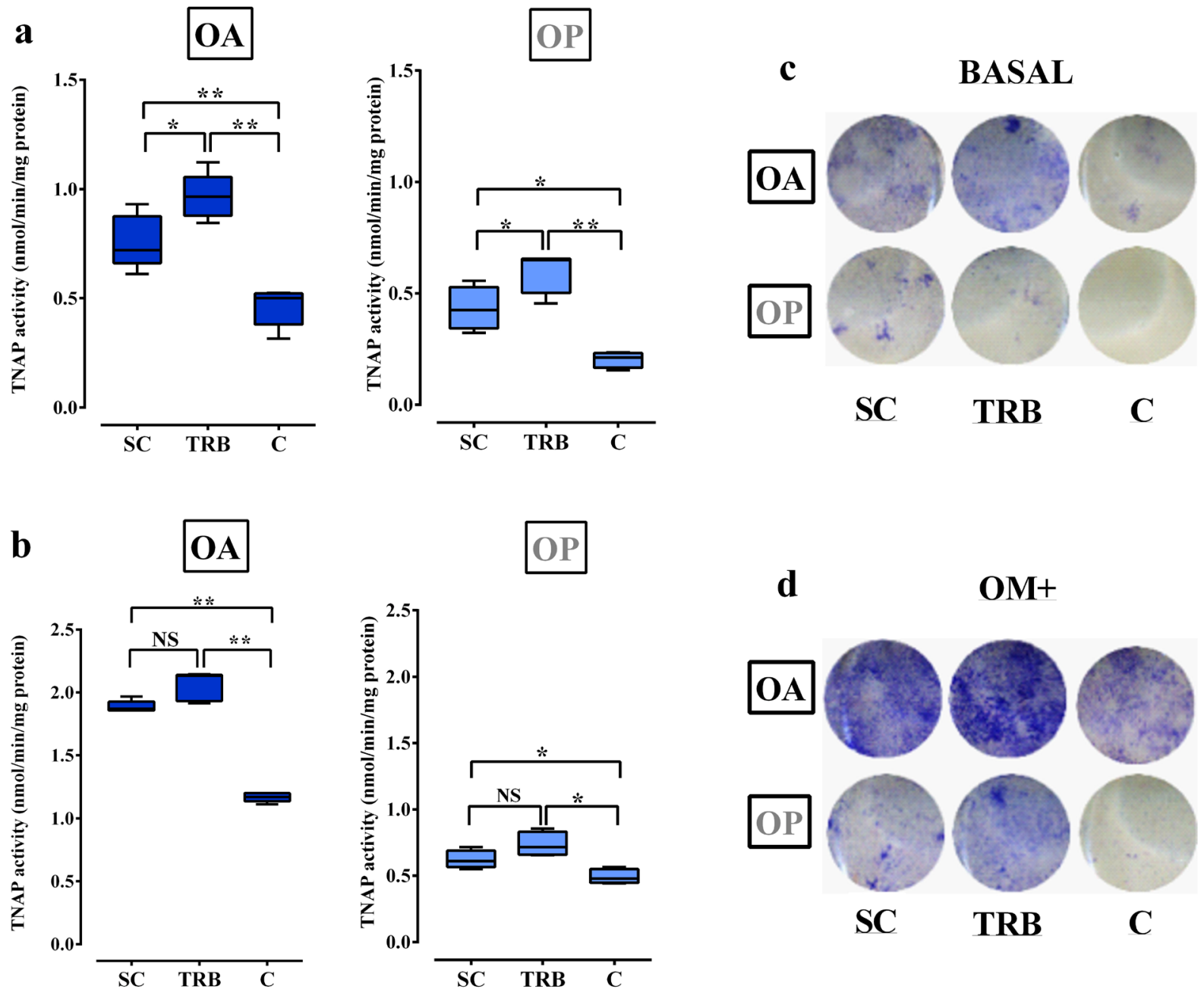

Fig. 4. TNAP in subchondral (SC), trabecular (TRB) and cortical (C) osteoblasts from form OA ( $n=5$ donors) (dark blue boxes) and OP ( $n=4$ donors) (light blue boxes) under basal and induced osteogenic conditions. Panel a: TNAP activity in OA and OP cells under basal conditions. Panel b: TNAP activity after osteogenic stimulation. TNAP was measured using p-nitro-phenyl phosphate as a substrate and normalised to total cellular lysate protein content. Results are expressed as the mean and $95 \% \mathrm{CI}$. *,** or *** indicates $p$-values less than $0.05,0.01$ or 0.001 respectively compared between osteoblast types. Comparisons between OA and OP for each osteoblast type resulted in $p$-values less than 0.01. Panel c, d: Representative images of fixed subchondral (SC), trabecular (TRB) and cortical (C) osteoblasts form OA ( $n=5$ donors) and OP ( $n=4$ donors). TNAP activity was assessed as described in the methods by the hydrolysis of naphthol AS-TR and fast blue precipitate under basal and osteogenic conditions. 
a

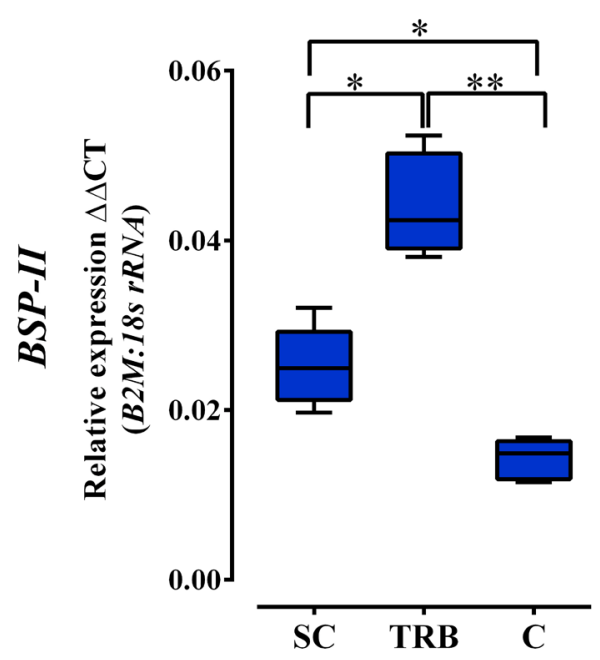

OA

c

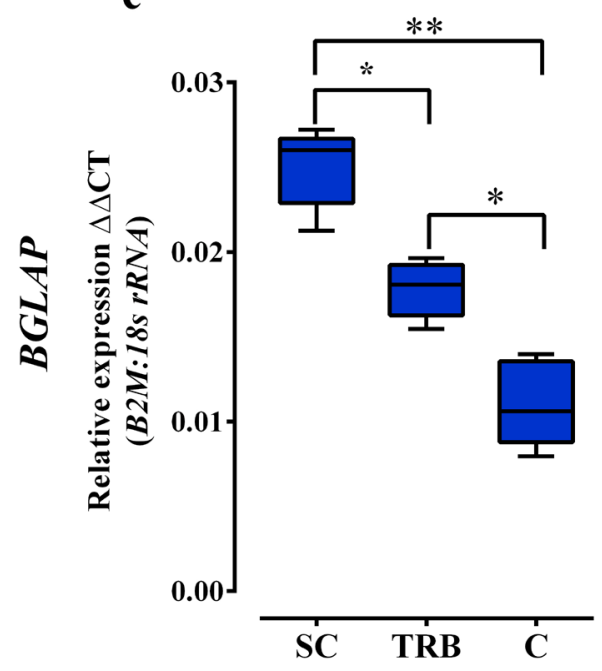

b
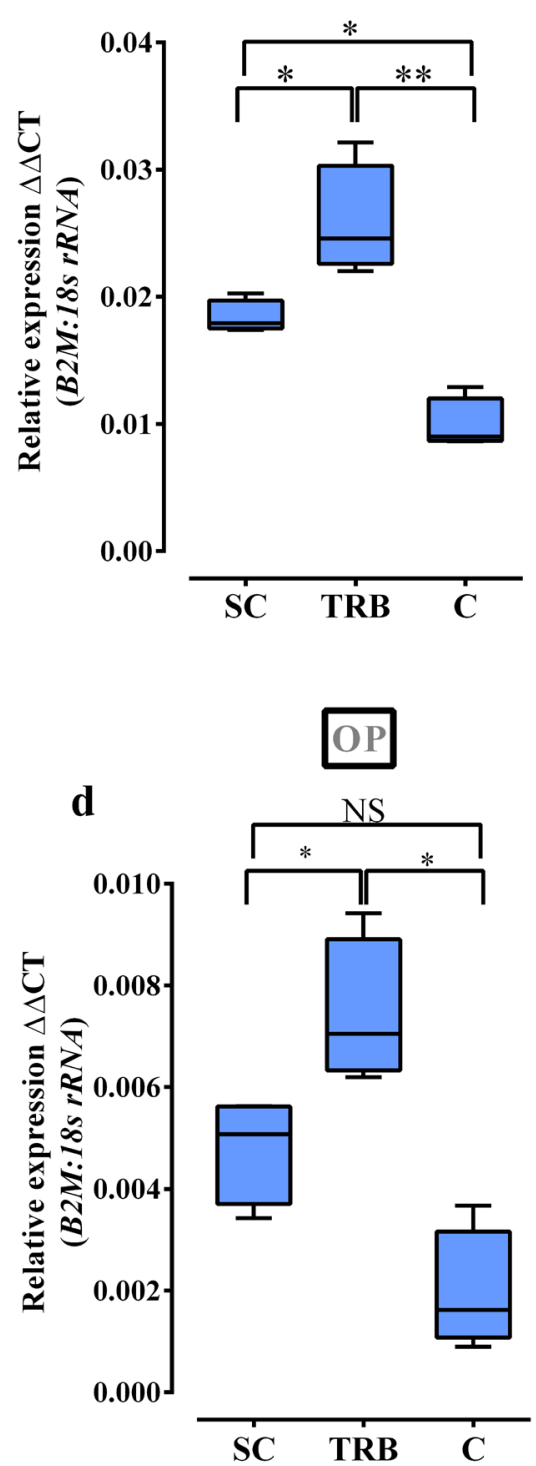

Fig. 5. Osteoblast maturation-related gene expression in subchondral (SC), trabecular (TRB) and cortical (C) osteoblasts derived from form OA ( $n=5$ donors) (dark blue boxes) and OP ( $n=4$ donors) (light blue boxes). BSP-II and BGLAP mRNA expression as the mean relative to the index of $\beta_{2}$-microglobulin: $18 \mathrm{~s} r R N A$ in arbitrary units and $95 \%$ CI. $*$ and ** indicates $p$-values less than 0.05 and 0.01 respectively compared between osteoblast types. Comparisons between OA and OP for each osteoblast type resulted in $p$-values less than 0.01

\section{Differential expression of maturation and bone matrix mineralisation genes in osteoblasts from different bone types}

To evaluate if mRNA transcripts for factors involved in controlling intrinsic bone cell maturation- capacity differed in the three bone cell types, we measured $B S P-I I$ and $B G L A P$ expression levels. In OA patients, we found that $B S P$-II mRNA levels were higher in trabecular- compared to subchondral-derived osteoblasts, which in turn were greater than in cortical osteoblasts (by $43 \%, p<0.05$ and $67 \%, p<0.05$, respectively) (Fig. 5a). Osteoblasts from OP patients also showed these bone type-related trends in $B S P-I I$ mRNA levels but were significantly lower than in osteoblasts from OA patients $(p<0.01)$ (Fig. 5b).
$B G L A P$ mRNA levels were, however, higher in subchondral bone osteoblasts then trabecular (31\%, $p<0.05)$ and cortical bone types $(56 \%, p<0.05)$ in OA patients (Fig. 5c). In contrast, in the OP patient group, trabecular osteoblasts exhibited the highest BGLAP mRNA levels compared to subchondral osteoblasts $(35 \%, p<0.05)$ and levels in the latter further exceeded levels observed in cortical osteoblasts $(73 \%, p<0.05)$. Subchondral osteoblasts exhibited greater BGLAP mRNA levels than cortical osteoblast in OP patient group, although not significantly (Fig. 5d). It was noted that osteoblasts from OP patients showed broadly similar patterns of $B S P-I I$ mRNA expression but that $B G L A P$ levels were markedly lower in all bone types in OP patients than corresponding 
Fig. 6. TNFRSF11B / TNFSF11 mRNA expression levels in subchondral (SC), trabecular (TRB) and cortical (C) osteoblasts derived from form OA ( $n=5$ donors) (dark blue boxes) and OP ( $n=4$ donors) (light blue boxes). TNFRSF11B (a, b) and TNFSF11 (c, d) mRNA expression are expressed as the mean expression relative to the index of $\beta$-microglobulin: $18 \mathrm{~s}$ $r R N A$ in arbitrary units and $95 \% \mathrm{CI}$. Ratio of TNFRSF $11 B$ and TNFSF 11 mRNA expression is expressed as the mean expression relative to the index of $\beta_{2}$-microglobulin: $18 \mathrm{~s}$ rRNA in arbitrary units and $95 \%$ CI. * and ** indicates $p$-values less than 0.05 and 0.01 respectively compared between osteoblast types. Comparisons between OA and OP for each osteoblast type resulted in $p$-values less than 0.01 .
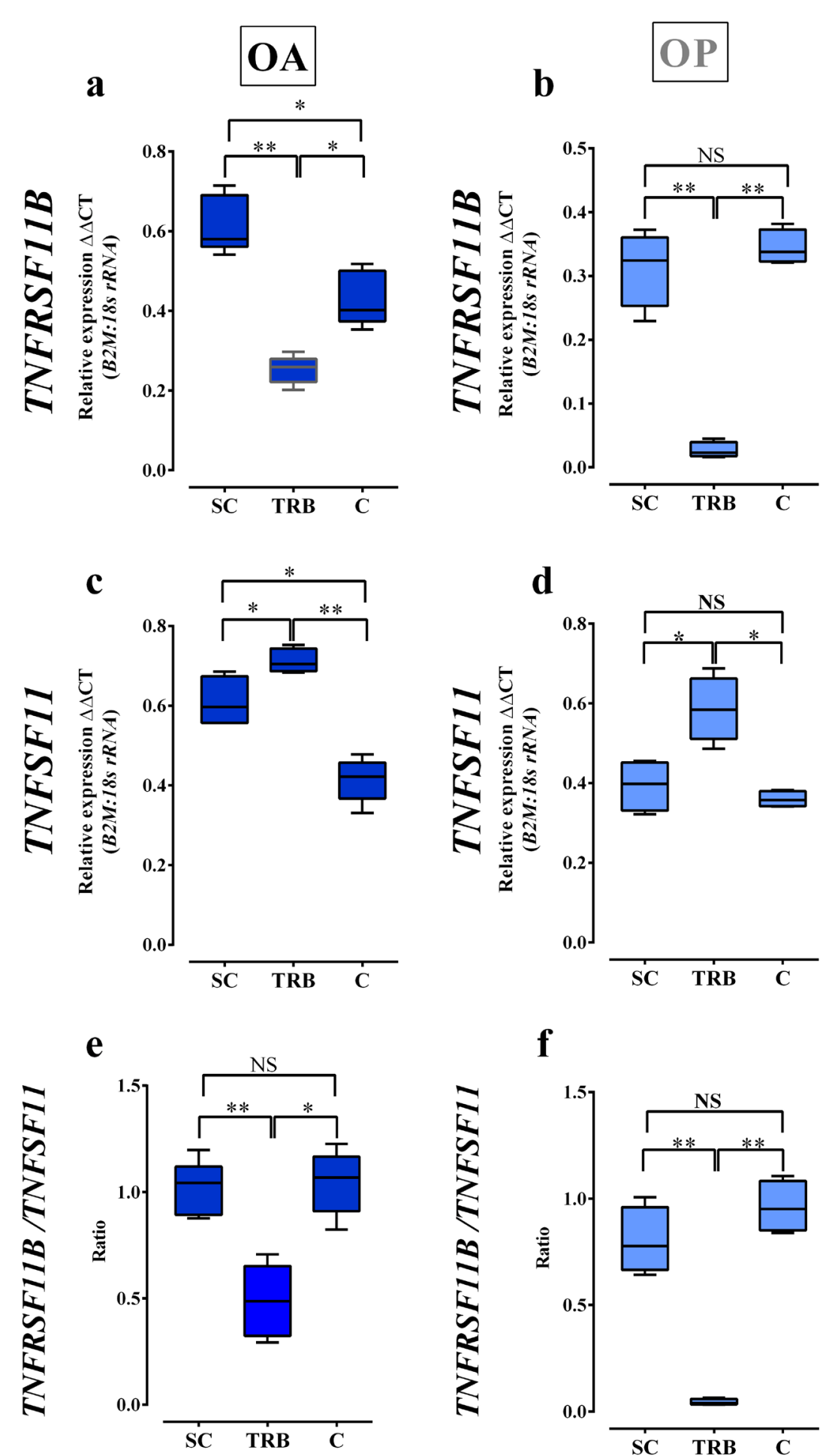

f

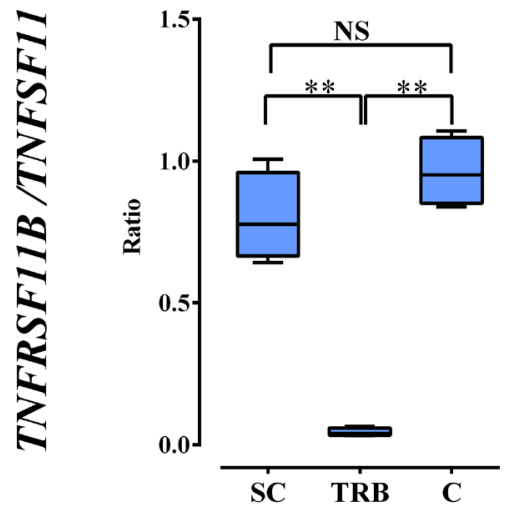

cells in the OA group $(p<0.01)$. Our preliminary studies using 'normal' bone samples showed that greatest $B S P$ $I I$ and $B G L A P$ mRNA levels were also observed in trabecular osteoblasts from this patient (Fig. 9g,h). These results illustrate bone type-related differences in markers involved in matrix synthesis and mineralisation and broad conservation of these patterns in distinct patient groups.

Subchondral and cortical human osteoblasts have decreased potential to stimulate osteoclastogenesis Having found that human osteoblasts exhibit characteristic growth/osteogenic differentiation behaviour in distinct bone types which is conserved across both OA and OP patient groups, we sought to establish by measuring levels of TNFRSF11B and TNFSF 11 mRNA, whether they might also exhibit divergent capacity to exert a paracrine influence on osteoclastogenesis. RANKL is expressed in osteoblasts and stimulates osteoclast formation and differentiation, while OPG is a RANKL decoy receptor also produced in osteoblasts (Atkins et al., 2003; Udagawa et al., 1999). Thus, TNFRSF11B /TNFSF11 ratios are often used as an index of osteoclastogenic potential. Our studies revealed virtually identical bone type-related differences in TNFRSF11B, TNFSF 11 and TNFRSF11B /TNFSF 11 ratios 
Fig. 7. $V E G F-A$ mRNA levels and protein release in subchondral (SC), trabecular (TRB) and cortical (C) osteoblasts derived from form OA ( $n=5$ donors) (dark blue boxes) and OP $(n=4$ donors) (light blue boxes). $V E G F-A$ mRNA expressed as the mean expression relative to the index of $\beta_{2}$-microglobulin: $18 s$ rRNA in arbitrary units and $95 \%$ CI (a, b). VEGF-A protein release as mean $\mathrm{ng}$ protein $/ \mu \mathrm{g}$ total RNA and $95 \%$ CI (c, d). $*$ and ** indicates $p$-values less than 0.05 and 0.01 respectively compared between osteoblast types. Comparisons between OA and OP for each osteoblast type resulted in $p$-values less than 0.01 .
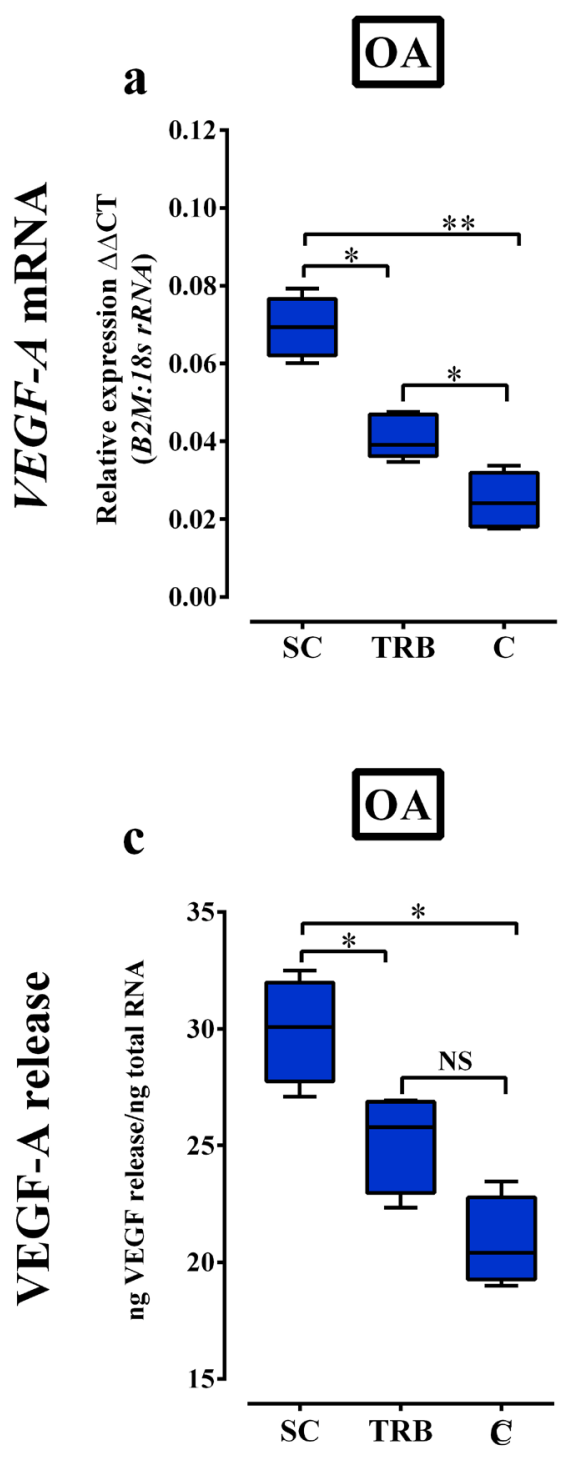
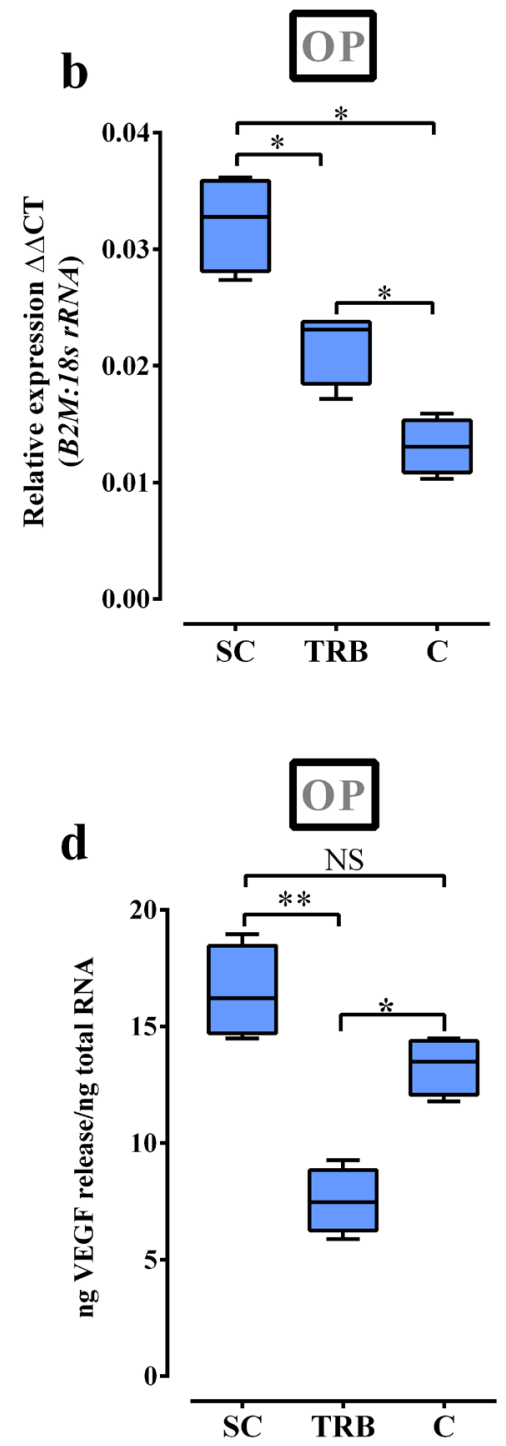

in OA and OP groups. Thus, TNFRSF11B mRNA levels were significantly higher in osteoblasts with subchondral and cortical bone origins compared to trabecular counterparts; TNFRSF11B mRNA levels in each bone type were also higher in OA compared to OP $(p<0.01)$ (Fig. $6 \mathbf{a}, \mathbf{b})$. In contrast, TNFSF 11 mRNA levels were greater in trabecular type osteoblasts than in subchondral $(p<0.05)$ and cortical osteoblasts in both OA and OP patients (Fig. 6c,d). TNFSF11 mRNA expression was higher in all sites in OA compared to OP osteoblasts $(p<0.01)$. Calculating TNFRSF11B /TNFSF11 ratios to determine a remodelling 'index' demonstrated that subchondral and cortical bone osteoblasts in both patient groups were equivalent, yet were consistently higher than in osteoblasts with trabecular bone origins in both OA and OP patients $(p<0.05)$ (Fig. 6e,f). Osteoblasts from normal bone showed some deviation from this trend, with greater ratios in subchondral osteoblasts than in cortical, and least in trabecular bone osteoblasts (Fig. 9i-k).

\section{Subchondral bone osteoblasts exhibit greatest} $V E G F-A$ mRNA expression and VEGF-A $\mathbf{A}_{165}$ release Osteoblast VEGF-A ${ }_{165}$ production is critical for coupling osteoblast and endothelial cell behaviour (Clarkin et al., 2008a; Clarkin and Olsen, 2010) and exerts a vital role in promoting osteogenesis in vivo (Liu et al., 2012). We therefore measured $V E G F-A$ mRNA expression levels and VEGF-A $_{165}$ protein release by osteoblasts. Subchondralderived osteoblasts expressed highest $V E G F-A$ mRNA levels in both OA and OP groups; greater by $48 \%(p<0.05)$ and $68 \%(p<0.05 \%)$ in OA, and by $21 \%(p<0.05)$ and $30 \%(p<0.05)$ compared to trabecular and cortical bone osteoblasts in OP, respectively (Fig. 7a,b). VEGF-A 165 protein levels in the medium conditioned by osteoblasts from different bone type origins followed similar patterns, with subchondral types consistently releasing highest levels in OA group (Fig. 7c). Subchondral-derived osteoblasts from OP patients demonstrated greatest VEGF-A ${ }_{165}$ release and least from trabecular bone osteoblasts (Fig. 7d). Our 
a

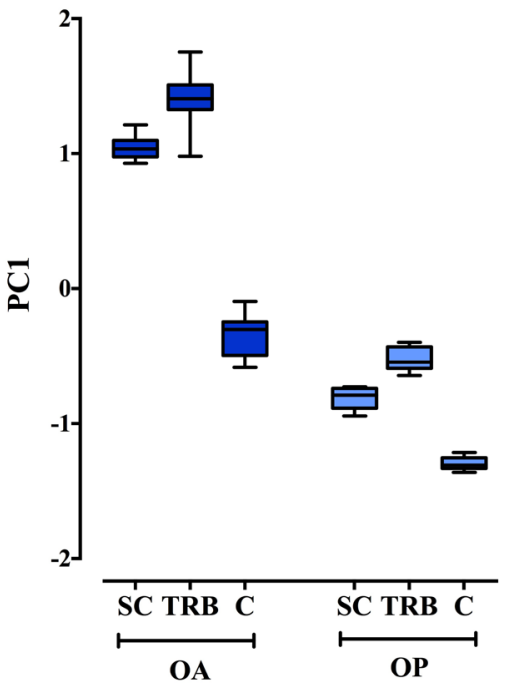

b

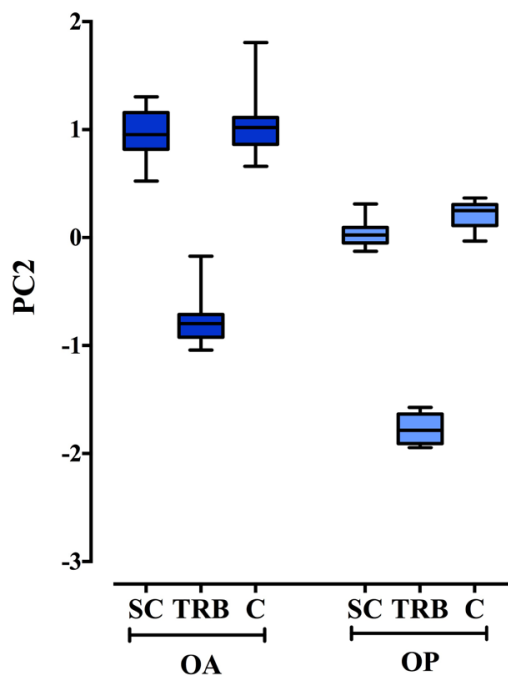

Fig. 8. Box plots illustrating $\mathrm{PC} 1(\mathbf{a})$ and PC2(b) (summarising the 16 parameters measured) demonstrating the similarities and differences between OA ( $n=5$ donors) (dark blue boxes) and OP ( $n=4$ donors $)$ (light blue boxes) and the three respective bone types.
Table 3. Table illustrating the 'component loading matrix' for the 16 variables tested. The values for component loading are analogous to correlation coefficients.

pilot studies using osteoblasts from a single set of normal bone samples showed that these osteoblasts produced (Fig. 9I,m) levels of VEGF-A ${ }_{165}$ release that was similar to OA (greatest in subchondral bone osteoblasts) and greater than in osteoblasts, from all three bone-types, in the OP group.

\section{Principal component analysis}

PCA is used to identify the main directions in which a dataset varies; the first PC accounts for as much variability in the entire data as possible, and each succeeding component accounts, in turn, for the highest variance possible that is unrelated to any preceding component. To better demonstrate significance in our data, we have therefore applied PCA to the entire data-set (16 variables). This discloses 2 components that explain $56 \%$ and $29 \%$ of all variation in the data. The component loading (Table 3 ) shows that the first component correlated most with TNAP mRNA and activity, VEGF-A mRNA and release levels, $R U N X 2, S P 7, B S P-I I$ and $B G L A P$ mRNA levels and less contribution from TNFRSF11B, TNFSF11, TNFRSF11B/ $T N F S F 11$ ratio and cell number (these 3 parameters were more correlated to component 2). For the first component the patterns between the OA and OP groups across bone types are similar, however, the difference between OA subchondral and trabecular osteoblasts compared to cortical osteoblasts was much greater than in the counterpart osteoblasts from the OP group ( $p<0.0001$ for interactions between bone types and patient groups) (Figure $8 \mathbf{a}$ ). For the second component, differences exist between $\mathrm{OA}$ and OP groups $(p<0.0001)$ and osteoblasts from trabecular type bone are different from both subchondral and cortical osteoblasts ( $p<0.0001$ for both comparisons), however no significant differences were observed between the subchondral and cortical osteoblasts in both patient groups $(p=0.078)$ (Figure 8b).

\begin{tabular}{|c|c|c|c|c|}
\hline \multirow{2}{*}{\multicolumn{3}{|c|}{ Component matrix }} & \multicolumn{2}{|c|}{ Components } \\
\hline & & & PC1 & $\mathrm{PC2}$ \\
\hline \multicolumn{3}{|c|}{ TNAP activity $(\mathrm{OM}+)$} & 0.976 & 0.149 \\
\hline \multicolumn{3}{|c|}{ Runx-2 mRNA } & 0.925 & -0.018 \\
\hline \multicolumn{3}{|c|}{ TNAP activity basal } & 0.924 & -0.246 \\
\hline \multicolumn{3}{|c|}{ TNAP mRNA 7 days } & 0.912 & -0.308 \\
\hline \multicolumn{3}{|c|}{$B G L A P$ mRNA } & 0.898 & 0.261 \\
\hline \multicolumn{3}{|c|}{ TNAP mRNA 24 hours } & 0.866 & -0.402 \\
\hline \multicolumn{3}{|c|}{ TNAP mRNA 14days } & 0.783 & -0.526 \\
\hline \multicolumn{3}{|c|}{ TNFRSF11B mRNA } & 0.776 & -0.531 \\
\hline \multicolumn{3}{|c|}{ VEGF-A release } & 0.760 & 0.583 \\
\hline \multicolumn{3}{|c|}{$V E G F-A$ mRNA } & 0.748 & 0.366 \\
\hline \multicolumn{3}{|c|}{ SP7 mRNA } & -0.666 & -0.615 \\
\hline \multicolumn{3}{|c|}{$B S P-I I$ mRNA } & 0.575 & -0.302 \\
\hline \multicolumn{3}{|c|}{ TNFRSF11B/TNFSF11 mRNA ratio } & -0.224 & 0.939 \\
\hline \multicolumn{3}{|c|}{ TNFSF11 mRNA } & 0.244 & 0.925 \\
\hline \multicolumn{3}{|c|}{ Cell Numbers } & 0.424 & 0.824 \\
\hline \multirow[b]{2}{*}{ Component } & \multicolumn{4}{|c|}{ Extraction Sums of Squared Loadings } \\
\hline & Total & $\%$ of Variance & \multicolumn{2}{|c|}{ Cumulative \% } \\
\hline PC1 & 8.468 & 56.456 & \multicolumn{2}{|c|}{56.456} \\
\hline $\mathrm{PC} 2$ & 4.328 & 28.855 & \multicolumn{2}{|c|}{85.311} \\
\hline
\end{tabular}

\section{Discussion}

Little consideration has previously been given to the exact origin of cells used for in vitro characterisation of osteoblast behaviour or those that are used in comparing osteoblasts from distinct disease states. Our study is the first to compare the behaviour of osteoblasts derived from structurally distinct bone compartments, namely the subchondral, trabecular and cortical bone types. Our comparison of osteoblasts derived from these three bone types from singular skeletal vicinity within the same patient adds strength to the study, as does their examination in 
a

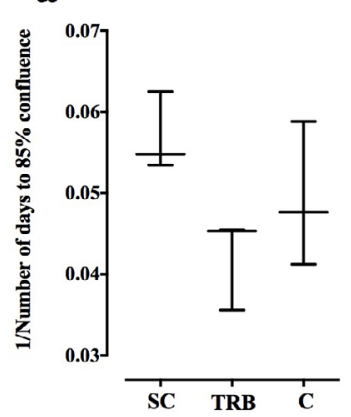

e
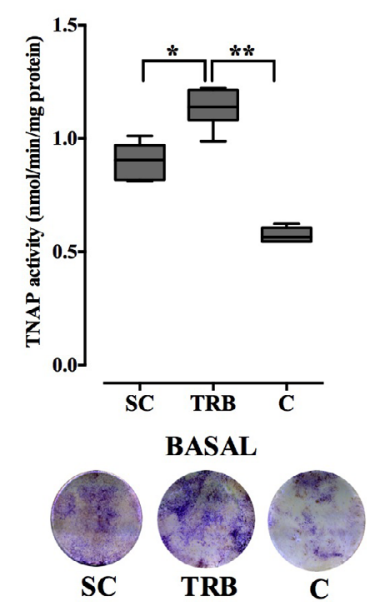

b

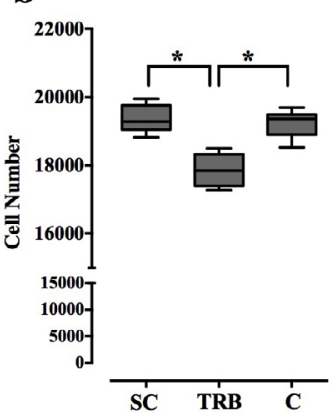

f

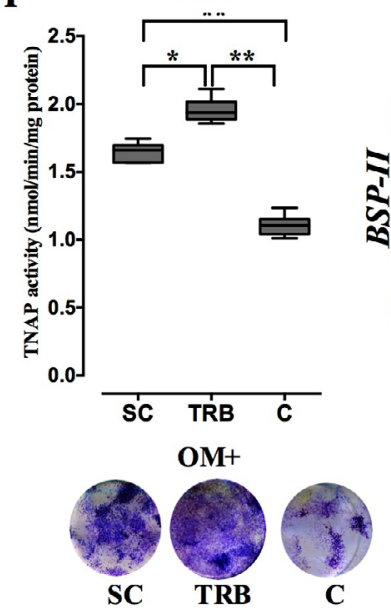

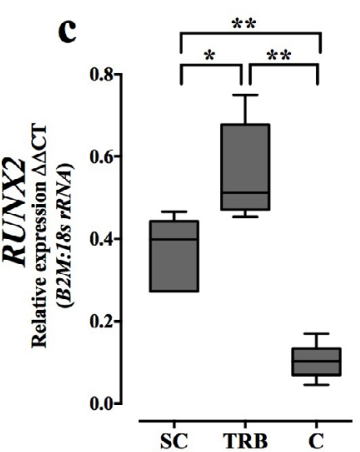

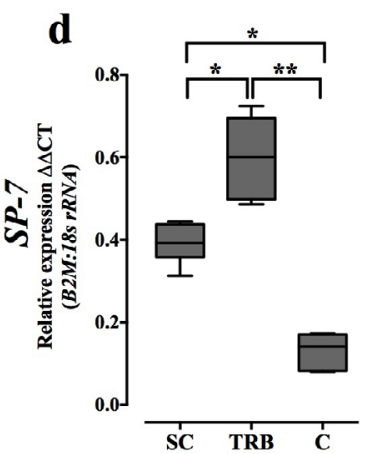

g

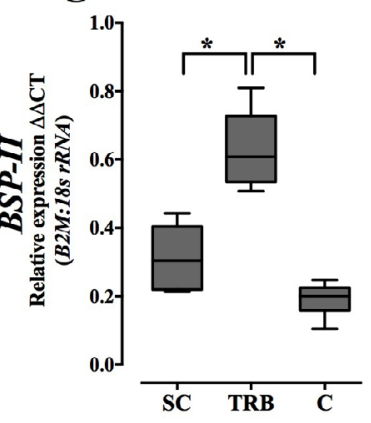

h

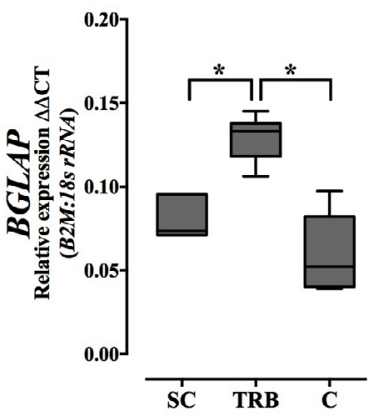

i

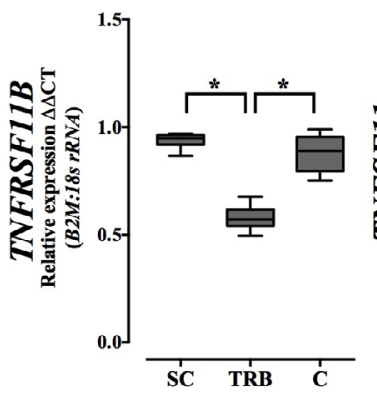

\section{j}

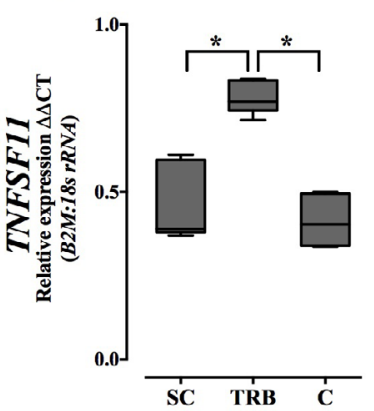

\section{k}

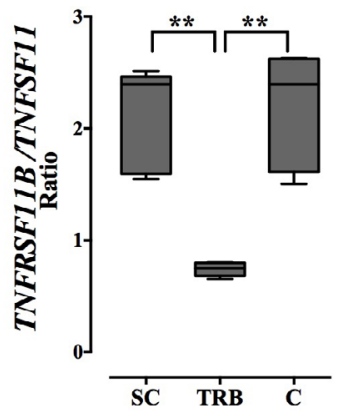

\section{1}
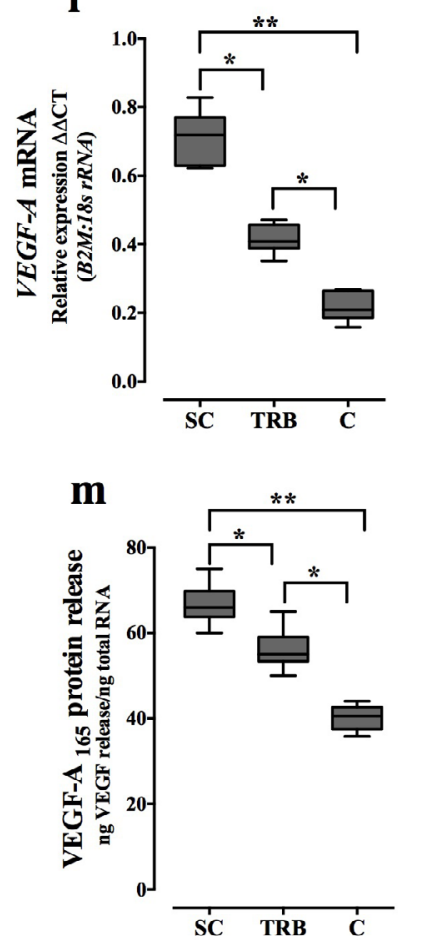

Fig. 9. Normal subchondral (SC), trabecular (TRB) and cortical (C) Human osteoblasts from a single patient exhibit modified growth characteristics. Panel a: rate of OB growth from specific types of bone explant (to $85 \%$ confluence). Panel b: OB cell growth from different bone types over 10 days measured by crystal violet staining and DAPI nuclear counting. Results are expressed as mean and $95 \%$ CI. Panel c, d: Osteogenic gene expression in osteoblast derived from different bone types in normal human patients. $R U N X-2$ and $S P-7$, mRNA expression levels expressed as the mean expression relative to the index of $\beta_{2}$-microglobulin: $18 s$ rRNA in arbitrary units and $95 \%$ CI. Panel e, f: Alkaline phosphatase activity in normal human osteoblasts from diverse bone types under basal and induced osteogenic conditions measured by quantitation of alkaline phosphatase activity. Representative images of ALP activity by staining with fast blue in human osteoblasts under basal and osteogenic conditions are presented beneath. Panel $\mathbf{g}$, h: Osteoblast maturation-related gene expression in osteoblast derived from different bone types in normal human patients. BSP-II and BGLAP mRNA expression levels expressed as the mean expression relative to the index of $\beta_{2}$-microglobulin: $18 s$ rRNA in arbitrary units and $95 \%$ CI. Panel i, j, k: TNFRSF11B / TNFSF11 mRNA expression levels expressed as the mean expression relative to the index of $\beta_{2}$-microglobulin: $18 s$ rRNA in arbitrary units and $95 \% \mathrm{CI}$. Panel $\mathbf{l}, \mathbf{m}$ : $V E G F-A$ mRNA levels and protein release in osteoblasts derived from different bone types in normal human patient samples. Results are expressed as mean and $95 \%$ CI. * and ** indicates $p$-values less than 0.05 and 0.01 respectively compared between osteoblast types. 
both OA and OP patient groups. We show specific bone type-related differences in growth, differentiation capacity and angiogenic potential of isolated osteoblasts maintained in vitro as well as a preservation of many such bone type-related differences in bone from both OA and OP patient groups. We find that osteoblasts from trabecular bone consistently show slower proliferation, but higher $R U N X 2, S P 7$ and BSP-II mRNA levels, TNAP mRNA and protein activity, and lower TNFRSF11B:TNFSF $11 \mathrm{mRNA}$ ratios compared to those from subchondral and cortical bone. Another consistent bone type-related difference are the higher levels of $V E G F-A$ mRNA and protein release by subchondral osteoblasts, implying more intimate vascular relationships for this bone type. Bone type-related behaviours were not, however conserved in OP and OA for all markers, with highest BGLAP mRNA levels in subchondral osteoblasts in OA and in trabecular osteoblasts in OP samples. Our data support inherent distinction in human osteoblasts from different bone types, likely due to positional or cellular progenitor origins and highlight the need to carefully select bone types when comparing osteoblasts in specific disease states.

Use of osteoblasts derived by primary outgrowth from bone samples is a vital component in bone biology studies (Czekanska et al., 2012). The method is most broadly applied to isolate osteoblasts from non-diseased or from neonatal murine bone tissues, which multiply to achieve outgrowth rapidly. Cells derived by outgrowth or by enzyme digestion are heterogeneous, consisting predominantly of early osteoblasts that show accelerated maturation (with matrix formation, mineralisation and osteogenic markers) in response to exogenous glucocorticoids, vitamin D or bone morphogenic proteins (Aubin et al., 1995; Beresford et al., 1993; Declercq et al., 2004; Lian and Stein, 1995; Liu et al., 1994; Liu et al., 1997; Siggelkow et al., 1999; Wong et al., 1990). Attainment of osteoblast confluence is significantly slower from the aged and diseased human bone samples used herein, than in other systems (Czekanska et al., 2012; Perinpanayagam et al., 2001; Siggelkow et al., 1999), yet is nonetheless comparable with outgrowth kinetics described previously in similar aged human bone samples (Couchourel et al., 2009; Couchourel D and Delalandre A, 2008; Hilal et al., 1998; Hilal et al., 2001; Massicotte et al., 2002; Tat et al., 2008). It is therefore striking and somewhat discordant with popular dogma (Dodds et al., 1989; Dodds et al., 1990; Varanasi et al., 2010) that we find initial osteoblast explant outgrowth to be slower in trabecular than in subchondral or cortical type bone. This bone type-related difference is unlikely due to a common underpinning disease mechanism as it is found in both $\mathrm{OA}$ and OP samples and in the samples from the single normal patient. While we cannot rule out whether these differences might additionally involve differential rates of apoptosis, our examination of growth differences, using direct cell counting and crystal violet staining of adherent viable cells after seeding at identical cell densities (Fig. 1b), demonstrate consistent trends in relative growth in the different bone types in OA and OP samples. These latter studies, where cell numbers were initially matched in cultures from all three bone types make it unlikely that divergent growth rates are due to inherent differences in bulk cellularity of the samples of these bone types with differing macrostructures, as remarkably similar inferiority in osteoblast growth is observed in trabecular-derived cells. Our findings are therefore consistent with the notion that primary osteoblasts derived by outgrowth from bone explants may not always be homologous and that their behaviour relies on functional and structural differences of their in vivo bone type origins.

These bone type-related cell differences may impact on physiological behaviour of osteoblasts in situ and consideration of bone's anabolic response to loading is perhaps particularly pertinent. It has for example been reported that oestrogen receptors appear to serve different roles in cortical and cancellous bone responses to loading in female and male mice (Saxon et al., 2012). We and others have also reported dissimilar in vivo loading responses in cortical and trabecular bone with ageing (De Souza et al., 2005; Willie et al., 2013). However, as these studies cannot calibrate for load-engendered strain in trabecular compartments it remains impossible to know whether these discrepant responses are due to differing inherent sensitivity to the load stimulus or instead reflect different levels of strain exposure. Comparison of several early responses to identical strains have, however, reported divergent in vitro behaviour in osteoblasts derived from calvaria and ulna, suggesting that inherent differences in strain sensitivity may exist (Rawlinson et al., 1995). More exploration is clearly required in order to establish whether bone type-related cell behaviours we describe, underpin differences in how bone compartments respond to anabolic stimuli in the physiological context.

There are several possible explanations for these inherent bone type-related differences in growth dynamics. Trabecular, cortical and subchondral bone clearly provide divergent topographies. Our studies do not allow us to estimate whether divergent in vivo architectures exert an influence on the osteoblasts derived, but 'compact' morphology of cortical and subchondral bone appears to endow greater proliferative capacity. If so, the underpinning mechanisms are retained even upon in vitro sub-seeding. Alternatively, trabecular-derived osteoblasts may reach a senescent state sooner, due to inherent differences in their 'Hayflick limit' (the number of times a cell population will divide until cell division is arrested; Hayflick, 1965). This might also explain the relative deficiency in osteoblasts derived from OP versus OA patients (evident in each of the three bone types) and also the relative exuberance of growth in osteoblasts derived from each of the bone types from the normal patient. This is intriguing because it indicates that regardless of the bone type sampled, OP osteoblasts exhibit a relative deficit in cell growth compared with OA (or the single normal samples), suggesting that this may reflect a widespread underpinning OP disease mechanism. Chronological ageing is also known to increase cellular senescence (Wagner et al., 2009) and others have shown that osteoblast growth declines with age in primary bone cells and stromal cells (Lajeunesse, 2002; Quarto et al., 1995; Zhang et al., 2008). Our data are also in line with studies by Giner et al. (Giner et al., 2009) showing that osteoblasts derived from OP patients exhibit 
slower proliferation than those from OA patients and consistent with another study demonstrating their deficient attachment to tissue culture plastic when compared in vitro (Perinpanayagam et al., 2001). Such patient-related differences do not however explain the consistent bone type-related divergence in growth exhibited by osteoblasts based upon their trabecular, subchondral and cortical bone origins. They are, however, in some agreement with additional studies demonstrating osteoblast heterogeneity in bone tissue (Dodds et al., 1989; Dodds et al., 1990) and bone cells extracted from different bone types and anatomical locations (Mcduffee et al., 2006; Ninomiya et al., 1990).

These positional or progenitor origins may also explain the bone type-related differences in differentiation potential we observed. We found that osteoblasts with trabecular origins exhibited greater $R U N X 2, S P 7$ and $B S P-I I$ mRNA levels and TNAP activity than subchondral or cortical type osteoblasts. Our study also evaluates the behaviour of subchondral-derived osteoblasts. Akin to trabecular bone osteoblasts, osteoblasts from subchondral type bone exhibited higher $R U N X 2, S P 7$ and $B S P-I I$ mRNA expression than cortical osteoblasts, but in contrast also displayed correspondingly high growth rates. Although expressed by other cells types where their functions remain incompletely defined (Choi et al., 2001; Jeong et al., 2008), RUNX2 and SP7 are considered master regulators of osteoblast differentiation (Ducy et al., 1997; Hartmann, 2009; Komori et al., 1997; Komori, 2006). Our study emphasises divergent RUNX2 and SP7 expression levels in osteoblasts from different bone types, which imply that subchondral osteoblasts possess greater inherent potential for in vitro growth and differentiation. Our data showing that levels of TNAP mRNA expression are maintained at $24 \mathrm{~h}, 7$ days and 14 days post confluence, support retention of this inherent difference in osteoblasts from divergent bone types. We thenceforth maintained cells for 36 days in basal media and $\mathrm{OM}+$ media and observed that trabecular osteoblasts exhibited greater ALP activities under basal and osteogenically stimulated conditions, further emphasising the inherent diversity in osteoblasts from these distinct bone types. Indeed, they are likely consistent with studies revealing different differentiation capacity in bone from neighbouring locations within single OA patient groups (Hilal et al., 2001; Lavigne et al., 2005; Westacott et al., 1997) and with recent studies describing distinct function and molecular properties in human haematopoietic stem cells in trabecular bone compartments from those located deeper in the marrow (Guezguez et al., 2013). Our studies highlight that osteoblasts from the different bone types showed matching disparity in both OA and OP patients. Furthermore, it is pertinent to stress that osteoblasts from OP patients exhibited a conserved deficiency in differentiation capacity, in each of the three bone types, when compared with either OA (or the single 'normal' patient); again indicating that OP may demonstrate systemic modification in bone cell function.

Previous studies using bone-seeking isotopes have led to a general acceptance that osteoblasts of trabecular bone have greater metabolic activity than those of the cortex and that this is retained in vitro due to the larger surface areas from which they are derived (Varanasi et al., 2010). Direct measurement of 'metabolic' activities of representative enzymes of the major oxidative pathways have shown that the reverse, in fact, pertained (Dodds et al., 1989; Dodds et al., 1990). Our data make the distinction between osteoblast growth and capacity of cells from dissimilar bone types to differentiate, demonstrating that the enhanced osteogenic markers and TNAP activity shown by osteoblasts from trabecular bone types is not necessarily allied to more rapid increases in cell number, which are evident in osteoblasts from subchondral bone types. These findings appear consistent with those of Solchaga et al. (Solchaga et al., 1998) in which greater TNAP activity and significantly higher mineral deposition was observed in cells derived from marrow than periosteum of rabbit tibiae; it is tempting to speculate that osteoblasts from trabeculartype bone more closely resemble the former and corticaltype osteoblasts the latter, respectively. It may be possible that the data presented in this study suggest an inherent diversity within the progenitor cell pool in these diverse bone types, which would require further investigations. If such inherent diversity does indeed exist, our findings demonstrating deficient growth and differentiation capacity in samples from OP patients would be consistent with a widespread scarcity of such progenitors.

Studies using human diseased bone samples have limitations. Foremost is the paucity of age/gender matched control samples from healthy, normal bone for comparison. Our efforts to redress this have generated pilot data from one set of normal bone samples and whilst these support identical bone type-related divergence in osteoblast behaviour, it is vital they are confirmed in multiple samples if more general conclusions regarding the impact of our findings are to be more broadly appreciated. In addition, we also acknowledge the possibility that primary cell culture cannot necessarily guarantee that all of the cells derived from different bone types are exactly the same. However, given that the method employed for primary cell isolation/ outgrowth from all three-bone types was identical, it is evident that the bone type-related differences in cell phenotype we have described highlight dissimilarities in their behaviour. Another limitation arises due to the slow growth and restricted cell numbers available from these samples. This restricts scope to perform analyses at multiple in vitro time-points and makes it unfeasible to use alternative methods, such as FACS analysis to quantify live/dead cells or surface markers. Direct observations during the cell growth phase nonetheless disclosed no obvious signs of apoptosis such as cell blebbing, shrinking or detachment. Another limitation is the lack of capacity to correlate our observations with one of the most important features of osteoblasts in vitro, namely their ability to deposit mineralised extracellular matrix. Our pilot studies showed that this capacity for mineralisation is highly compromised in osteoblasts derived from OA and OP bone samples, with little mineralisation even after 56 days (data not shown; compared with overt mineralisation by 36 days in normal human cultures). This deficiency in mineralisation was greater in OP patient cells compared to OA. Our findings are in agreement with studies by Siggelkow and colleagues (Siggelkow et al., 1999) 
and those showing that mineralisation in OA derived subchondral osteoblasts is compromised compared to those from normal (Couchourel et al., 2009). This diseaserelated lack of mineralisation may be compounded by the advanced age of patients acting as bone donors in this study, and with respect to OP osteoblasts it may be a consequence of the disease and further elucidation of the underpinning mechanisms would be required.

Somewhat surprisingly the only significant deviation from the consistent bone type-related osteoblast differentiation markers seen in OP and OA groups was the elevated BGLAP mRNA levels in subchondral osteoblasts in the OA patients and in the trabecular osteoblasts of patients with OP. The latter is completely in line with the relatively elevated levels of all other markers of osteoblast differentiation measured in the trabecular osteoblast of OP patients, but the former raises an interesting paradox particular to OA patients, suggesting that this is more likely disease-specific. This is supported by previous studies demonstrating elevated BGLAP mRNA levels in subchondral bone regions in OA patients, which is further exaggerated in sclerotic ( $v s$. non sclerotic) regions (Sanchez et al., 2008). It is likely that application of similar approaches, restricting the study of osteoblast behaviour in disease to only direct comparison within single, specific bone types, is likely to reduce experimental inhomogeneity and speed identification of underpinning disease mechanisms.

This is perhaps accentuated by studies distinguishing two separate groups of subchondral bone OA osteoblasts: 'low' - which resemble normal osteoblasts - and 'high' osteoblasts with corresponding prostaglandin $\mathrm{E}_{2}$ and IL-6 levels (Hilal et al., 2001; Massicotte et al., 2002). More recent data indicate a close relationship between these OA subchondral osteoblasts and the OPG/RANK/ RANKL system, linking to structural bone changes in OA (Tat et al., 2008; Tat et al., 2009). It was found that 'low' osteoblasts express depleted TNFRSF11B, but high TNFSF11 levels, whereas 'high' OA osteoblasts express the reverse (Tat et al., 2008). Consideration of these findings in the light of our own, which shows that trabecular type osteoblasts express lower TNFRSF11B:TNFSF11 ratios compared to subchondral and cortical osteoblasts, implies that 'low' - more normal - subchondral osteoblasts show greater resemblance with those derived from trabecular compartments. It is also pertinent that lower osteoblast TNFRSF 11B:TNFSF 11 ratios (observed in OP osteoblasts) are likely to promote bone resorption assuming correlative post-translational trends, suggesting that such remodelling activities will predominate in trabecular type bone and will also be more marked in bone from OP than OA (and normal) patient groups. RANKL and OPG protein levels were not measured herein, however previous studies have demonstrated close correlation of osteogenic protein expression to mRNA levels (Born et al., 2009; Deyama et al., 2000; Hofbauer et al., 1999; Rickard et al., 1996; Shea et al., 2000).

The possibility that osteoblasts from subchondral, cortical and trabecular bone types might exert differential recruitment of osteoclasts from the vasculature, prompted studies into their potential capacity to also control angiogenesis. Osteogenesis and angiogenesis are closely related processes that are intimately linked during bone development, growth, remodelling and fracture repair (Clarkin et al., 2008a; Clarkin and Gerstenfeld, 2013; Clarkin and Olsen, 2010). VEGF has emerged as an essential component promoting this relationship (Fazzalari, 2011; Hankenson et al., 2011; Marsell and Einhorn, 2011) and its intracellular effects have recently been shown to promote osteogenesis at the expense of adipogenesis (Liu et al., 2012). We therefore measured their relative mRNA levels and release of secreted VEGF (Clarkin et al., 2008a). This revealed a clear hierarchy in $V E G F-A$ mRNA levels in OA and OP (and normal samples from a single patient) bone types, with highest levels in subchondral, followed by trabecular and cortical-derived osteoblasts; it was also clear that OA consistently exceeded levels in OP patients (and more akin to normal). These data accord with those of Sanchez et al. (Sanchez et al., 2008) and imply that osteoblasts from subchondral bone (amongst those examined herein) have the most intimate relationship with the vasculature, particularly in OA, which may contribute to osteochondral OA pathophysiology. The basis of the consistently lower bone type-matched VEGF mRNA (and protein) levels in OP samples is also intriguing and may reflect the greater susceptibility to fracture in OP than OA patients; this however requires further exploration. VEGF-A ${ }_{165}$ protein levels in conditioned media from osteoblasts also generally match those for mRNA expression, with one exception. Thus, while $V E G F-A$ mRNA levels were higher in trabecular than corticalderived osteoblasts from OP patients, relative VEGF-A ${ }_{165}$ protein levels were significantly lower. This suggests some impairment in VEGF translation or post-translational VEGF degradation in OP trabecular bone osteoblasts, but is nonetheless consistent with the altered proangiogenic signalling of bone reported in these patients (Burkhardt et al., 1987; Ding et al., 2011; Xia et al., 2012). Indeed, it has been shown that primary OA and OP osteoblasts express differential VEGF-A levels (Corrado et al., 2013), which are in line with our findings. The demonstration of elevated $V E G F-A$ expression in metaphyseal versus diaphyseal periosteal locations in osteoporotic rats (Fan et al., 2010) further illustrates the requirement to explore variations in the communication by osteoblasts to the vasculature, which is critical for bone maintenance and repair, in different bones types. Since VEGF is central to coupling angiogenesis in bone healing, our data raise the intriguing possibility that osteoblasts from different bone types exhibit divergent potential for VEGF-mediated crosstalk with the vasculature, with those in subchondral bone having a relative advantage (Fazzalari, 2011; Report of a WHO study Group, 1994; Sarahrudi et al., 2009).

Our study identifies basal differences in primary osteoblast behaviour that are linked to the diversity in the type, or category of bone. We cannot be sure that these bone type-related attributes are necessarily replicated at all other skeletal locations or are conserved in all species. They are, however, reinforced significantly by a preservation of many of these differences in the distinct OA and OP patient 
groups (and a single set of samples from a normal patient) examined and this illustrates that these characteristics do not simply reflect disease manifestation but are rather bone type-related in human specimens.

\section{Conclusion}

Although the importance of our findings would be greatly extended if similar bone type-related behaviours were confirmed, with the inclusion of more replicates of normal human bone osteoblasts, our data support the hypothesis that osteoblasts in trabecular, subchondral and cortical bone regions of the human skeleton have inherent, programmed diversity in their behaviour. It is tempting to speculate that this may extend to definable divergence in their responses to soluble and mechanical extracellular cues and systemic factors, and that such elucidation will allow for specific bone type-selective regulation. This raises a major caveat in our study; as it is possible osteoblasts from these different bone types only exhibit such divergence in behaviour in human shoulder joint samples. This accentuates a need for further studies to address whether this paradigm is extended to other skeletal elements. It is also possible that the differences uncovered by our studies are related to the developmental origins of the osteoblasts in these types of bones (Rawlinson et al., 2009). Our studies have shown that primary osteoblasts derived from diverse trabecular, cortical and subchondral bone types from within a single anatomical location have distinctive growth, differentiation, remodelling and pro-angiogenic characteristics, which may underpin some of the divergent behaviour of bone at these sites. Our studies also reveal that osteoblasts derived from all three types of bone from OP patients exhibit diminished growth, differentiation and pro-angiogenic signalling than counterparts from $\mathrm{OA}$ patients, suggesting that such deficit may be systemic, rather than local. With further studies to validate these conclusions, this work may also provide further rationale for development and design of new implants that target specific bone types in order to avoid complications associated with use of long stemmed prosthesis and their redesign to harness greatest pro-angiogenic capacity and fracture healing. Further investigations are clearly required to explore this potential.

\section{Acknowledgments}

Orthopaedic Research UK (ORUK) gracefully funded this project. We would thank all the surgical teams at $\mathrm{St}$ Mary's Hospital, Charing Cross Hospital and Chelsea Westminster Hospital for their assistance in helping with sample collections. We would like to thank Prof Adrienne Flanagan, Mr Rob Pollock and the Biobank at the Royal National Orthopaedic Hospital for the provision and assistance in obtaining normal tissue samples. Finally we gracefully acknowledge and appreciate Yu-Mei Chang for her expert assistance with statistical testing.

\section{References}

Aerssens J, Boonen S, Joly J, Dequeker J (1997) Variations in trabecular bone composition with anatomical site and age: potential implications for bone quality assessment. J Endocrinol 155: 411-421.

Akintoye SO, Lam T, Shi S, Brahim J, Collins MT, Robey PG (2006) Skeletal site-specific characterization of orofacial and iliac crest human bone marrow stromal cells in same individuals. Bone 38: 758-768.

Atkins GJ, Kostakis P, Pan B, Farrugia A, Gronthos S, Evdokiou A, Harrison K, Findlay DM, Zannettino ACW (2003) RANKL expression is related to the differentiation state of human osteoblasts. J Bone Miner Res 18: 10881098.

Atkins GJ, Rowe PS, Lim HP, Welldon KJ, Ormsby R, Wijenayaka AR, Zelenchuk L, Evdokiou A, Findlay DM (2011) Sclerostin is a locally acting regulator of late-osteoblast/preosteocyte differentiation and regulates mineralization through a MEPE-ASARM-dependent mechanism. J Bone Miner Res 26: 1425-1436.

Aubin JE, Lui F, Malaval L, Gupta AK (1995) Osteoblast and chondroblast differentiation. Bone 17 Suppl 2:77S-83S.

Beresford JN, Graves SE, Smoothy CA (1993) Formation of mineralized nodules by bone derived cells in vitro: a model of bone formation? Am J Med Genet 45: 163-178.

Bohsali KI, Wirth MA, Rockwood Jr. CA (2006) Complications of total shoulder arthroplasty. J Bone Joint Surg Am 88: 2279-2292.

Born A-K, Rottmar M, Lischer S, Pleskova M, Bruinink A, Maniura-Weber K (2009) Correlating cell architecture with osteogenesis: first steps towards live single cell monitoring. Eur Cell Mater 18: 49-62.

Bultink IEM, Lems WF (2013) Osteoarthritis and osteoporosis: what is the overlap? Curr Rheumatol Rep 15: 328 .

Burkhardt R, Kettner G, Böhm W, Schmidmeier M, Schlag R, Frisch B, Mallmann B, Eisenmenger W, Gilg T (1987) Changes in trabecular bone, hematopoiesis and bone marrow vessels in aplastic anemia, primary osteoporosis, and old age: a comparative histomorphometric study. Bone 8: $157-164$.

Bustin SA, Benes V, Garson JA, Hellemans J, Huggett J, Kubista M, Mueller R, Nolan T, Pfaffl MW, Shipley GL, Vandesompele J, Wittwer CT (2009) The MIQE guidelines: minimum information for publication of quantitative realtime PCR experiments. Clin Chem 55: 611-622.

Candeliere GA, Liu F, Aubin JE (2001) Individual osteoblasts in the developing calvaria express different gene repertoires. Bone 28: 351-361.

Choi JY, Pratap J, Javed A, Zaidi SK, Xing L, Balint E, Dalamangas S, Boyce B, van Wijnen a J, Lian JB, Stein JL, Jones SN, Stein GS (2001) Subnuclear targeting of Runx/Cbfa/AML factors is essential for tissue-specific differentiation during embryonic development. Proc Natl Acad.Sci U S A 98: 8650-8655.

Clarkin CE, Allen S, Wheeler-Jones CP, Bastow ER, Pitsillides AA (2011) Reduced chondrogenic matrix accumulation by 4-methylumbelliferone reveals 
the potential for selective targeting of UDP-glucose dehydrogenase. Matrix Biol 30: 163-168.

Clarkin CE, Emery RJ, Pitsillides AA, Wheeler-Jones CPD (2008a) Evaluation of VEGF-mediated signaling in primary human cells reveals a paracrine action for VEGF in osteoblast-mediated crosstalk to endothelial cells. J Cell Physiol 214: 537-544.

Clarkin CE, Garonna E, Pitsillides AA, WheelerJones CPD (2008b) Heterotypic contact reveals a COX2-mediated suppression of osteoblast differentiation by endothelial cells: a negative modulatory role for prostanoids in VEGF-mediated cell: cell communication? Exp Cell Res 314: 3152-3161.

Clarkin CE, Gerstenfeld LC (2012) VEGF and bone cell signalling : an essential vessel for communication ? Cell Biochem Funct 31: 1-11.

Clarkin C, Olsen BR (2010) On bone-forming cells and blood vessels in bone development. Cell Metab 12: 314-316.

Corrado A, Neve A, Cantatore FP (2013) Expression of vascular endothelial growth factor in normal, osteoarthritic and osteoporotic osteoblasts. Clin Exp Med 13: 81-84.

Couchourel D, Delalandre ALD (2008) Increased expression of Wnt inhibitory factors in subchondral osteoblasts from osteoarthritic patients could play a role in their abnormal phenotype and mineralization. Ann Rheum Dis, 67 suppl 2 : 98.

Couchourel D, Aubry I, Delalandre A, Lavigne M, Martel-Pelletier J, Pelletier J-P, Lajeunesse D (2009) Altered mineralization of human osteoarthritic osteoblasts is attributable to abnormal type I collagen production. Arthritis Rheum 60: 1438-1450.

Czekanska EM, Stoddart MJ, Richards RG, Hayes JS (2012) In search of an osteoblast cell model for in vitro research. Eur Cell Mater 24: 1-17.

Declercq H, Van Den Vreken N, De Maeyer E, Verbeeck R, Schacht E, De Ridder L, Cornelissen M (2004) Isolation, proliferation and differentiation of osteoblastic cells to study cell/biomaterial interactions: comparison of different isolation techniques and source. Biomaterials 25: 757-768.

Dequeker J, Burssens A, Creytens G, Bouillon R (1975) Ageing of bone: its relation to osteoporosis and osteoarthrosis in postmenopausal women. Front Horm Res 3: 116-130.

Deyama Y, Takeyama S, Koshikawa M, Shirai Y, Yoshimura Y, Nishikata M, Suzuki K, Matsumoto A (2000) Osteoblast maturation suppressed osteoclastogenesis in coculture with bone marrow cells. Biochem Biophys Res Commun 274: 249-254.

Dillon JP, Waring-Green VJ, Taylor AM, Wilson PJM, Birch M, Gartland A, Gallagher JA (2012) Primary human osteoblast cultures. Methods Mol Biol 816: 3-18.

Ding M, Odgaard A, Linde F, Hvid I (2002) Age-related variations in the microstructure of human tibia cancellous bone. J Orthop Res 20: 615-621.

Ding W-G, Wei Z-X, Liu J-B (2011) Reduced local blood supply to the tibial metaphysis is associated with ovariectomy-induced osteoporosis in mice. Connect Tissue Res 52: 25-29.

Dodd AW, Syddall CM, Loughlin J (2012) A rare variant in the osteoarthritis-associated locus GDF5 is functional and reveals a site that can be manipulated to modulate GDF5 expression. Eur J Hum Genet 21: 517-521.

Dodds RA, Emery RJ, Klenerman L, Chayen J, Bitensky L (1989) Comparative metabolic enzymatic activity in trabecular as against cortical osteoblasts. Bone 10: $251-254$.

Dodds RA, Emery RJ, Klenerman L, Chayen J, Bitensky L (1990) Selective depression of metabolic activities in cortical osteoblasts at the site of femoral neck fractures. Bone 11: 157-161.

Ducy P, Zhang R, Geoffroy V, Ridall AL, Karsenty G (1997) Osf2/Cbfa1: a transcriptional activator of osteoblast differentiation. Cell 89: 747-754.

Estrada K, Styrkarsdottir U, Evangelou E, Hsu Y-H, Duncan EL, Ntzani EE, Oei L, Albagha OME, Amin N, Kemp JP, Koller DL, Li G, Liu C-T, Minster RL, Moayyeri A, Vandenput L, Willner D, Xiao S-M, Yerges-Armstrong LM, Zheng H-F, Alonso N, Eriksson J, Kammerer CM, Kaptoge SK, Leo PJ, Thorleifsson G, Wilson SG, Wilson JF, Aalto V, Alen M, Aragaki AK, Aspelund T, Center JR, Dailiana Z, Duggan DJ, Garcia M, Garcia-Giralt N, Giroux S, Hallmans G, Hocking LJ, Husted LB, Jameson KA, Khusainova R, Kim GS, Kooperberg C, Koromila T, Kruk M, Laaksonen M, Lacroix AZ, Lee SH, Leung PC, Lewis JR, Masi L, Mencej-Bedrac S, Nguyen T V, Nogues X, Patel MS, Prezelj J, Rose LM, Scollen S, Siggeirsdottir K, Smith AV, Svensson O, Trompet S, Trummer O, van Schoor NM, Woo J, Zhu K, Balcells S, Brandi ML, Buckley BM, Cheng S, Christiansen C, Cooper C, Dedoussis G, Ford I, Frost M, Goltzman D, González-Macías J, Kähönen M, Karlsson M, Khusnutdinova E, Koh J-M, Kollia P, Langdahl BL, Leslie WD, Lips P, Ljunggren Ö, Lorenc RS, Marc J, Mellström D, Obermayer-Pietsch B, Olmos JM, Pettersson-Kymmer U, Reid DM, Riancho JA, Ridker PM, Rousseau F, Slagboom PE, Tang NLS, Urreizti R, Van Hul W, Viikari J, Zarrabeitia MT, Aulchenko YS, CastanoBetancourt M, Grundberg E, Herrera L, Ingvarsson T, Johannsdottir H, Kwan T, Li R, Luben R, Medina-Gómez C, Palsson ST, Reppe S, Rotter JI, Sigurdsson G, van Meurs JBJ, Verlaan D, Williams FMK, Wood AR, Zhou Y, Gautvik KM, Pastinen T, Raychaudhuri S, Cauley JA, Chasman DI, Clark GR, Cummings SR, Danoy P, Dennison EM, Eastell R, Eisman JA, Gudnason V, Hofman A, Jackson RD, Jones G, Jukema JW, Khaw K-T, Lehtimäki T, Liu Y, Lorentzon M, McCloskey E, Mitchell BD, Nandakumar K, Nicholson GC, Oostra BA, Peacock M, Pols HAP, Prince RL, Raitakari O, Reid IR, Robbins J, Sambrook PN, Sham PC, Shuldiner AR, Tylavsky FA, van Duijn CM, Wareham NJ, Cupples LA, Econs MJ, Evans DM, Harris TB, Kung AWC, Psaty BM, Reeve J, Spector TD, Streeten EA, Zillikens MC, Thorsteinsdottir U, Ohlsson C, Karasik D, Richards JB, Brown MA, Stefansson K, Uitterlinden AG, Ralston SH, Ioannidis JPA, Kiel DP, Rivadeneira F (2012) Genome-wide meta-analysis identifies 56 bone mineral density loci and reveals 14 loci associated with risk of fracture. Nat Genet 44: 491-501.

Fan W, Bouwense SAW, Crawford R, Xiao Y (2010) Structural and cellular features in metaphyseal and diaphyseal periosteum of osteoporotic rats. J Mol Histol 41: 51-60. 
Fazzalari NL (2011) Bone fracture and bone fracture repair. Osteoporos Int 22: 2003-2006.

Galea GL, Meakin LB, Sugiyama T, Zebda N, Sunters A, Taipaleenmaki H, Stein GS, van Wijnen AJ, Lanyon LE, Price JS (2013) Estrogen receptor $\alpha$ mediates proliferation of osteoblastic cells stimulated by estrogen and mechanical strain, but their acute down-regulation of the Wnt antagonist Sost is mediated by estrogen receptor $\beta$. J Biol Chem 288: 9035-9048.

Gallagher JA, Gundle R, Beresford JN (1996) Isolation and culture of bone-forming cells (osteoblasts) from human bone. Methods Mol Med 2: 233-262.

Gartland A, Rumney RMH, Dillon JP, Gallagher JA (2012) Isolation and culture of human osteoblasts. Methods Mol Biol 806: 337-355.

Giner M, Rios MJ, Montoya MJ, Vázquez MA, Naji L, Pérez-Cano R (2009) RANKL/OPG in primary cultures of osteoblasts from post-menopausal women. Differences between osteoporotic hip fractures and osteoarthritis. J Steroid Biochem Mol Biol 113: 46-51.

Grigoriadis AE, Heersche JN, Aubin JE (1988) Differentiation of muscle, fat, cartilage, and bone from progenitor cells present in a bone-derived clonal cell population: effect of dexamethasone. J Cell Biol 106: 2139-2151.

Guezguez B, Campbell CJV, Boyd AL, Karanu F, Casado FL, Di Cresce C, Collins TJ, Shapovalova Z, Xenocostas A, Bhatia M (2013) Regional localization within the bone marrow influences the functional capacity of human HSCs. Cell Stem Cell 13: 175-189.

Hankenson KD, Dishowitz M, Gray C, Schenker M (2011) Angiogenesis in bone regeneration. Injury 42: 556561.

Hartmann C (2009) Transcriptional networks controlling skeletal development. Curr Opin Genet Dev 19: 437-443.

Hayflick L (1965) The limited in vitro lifetime of human diploid cell strains. Exp Cell Res 37: 614-636.

Hilal G, Martel-Pelletier J, Pelletier JP, Ranger P, Lajeunesse D (1998) Osteoblast-like cells from human subchondral osteoarthritic bone demonstrate an altered phenotype in vitro: possible role in subchondral bone sclerosis. Arthritis Rheum 41: 891-899.

Hilal G, Massicotte F, Martel-Pelletier J, Fernandes JC, Pelletier JP, Lajeunesse D (2001) Endogenous prostaglandin E2 and insulin-like growth factor 1 can modulate the levels of parathyroid hormone receptor in human osteoarthritic osteoblasts. J Bone Miner Res 16: 713-721.

Hildyard JCW, Wells DJ (2014) Identification and validation of quantitative PCR reference genes suitable for normalizing expression in normal and dystrophic cell culture models of myogenesis. PLoS Curr 6: 1-23.

Hofbauer LC, Gori F, Riggs BL, Lacey DL, Dunstan CR, Spelsberg TC, Khosla S (1999) Stimulation of osteoprotegerin ligand and inhibition of osteoprotegerin production by glucocorticoids in human osteoblastic lineage cells: potential paracrine mechanisms of glucocorticoidinduced osteoporosis. Endocrinology 140: 4382-4389.

Jagodzinski M, Drescher M, Zeichen J, Hankemeier S, Krettek C, Bosch U, van Griensven M (2004) Effects of cyclic longitudinal mechanical strain and dexamethasone on osteogenic differentiation of human bone marrow stromal cells. Eur Cell Mater 7: 35-41.

Jeong JH, Jin JS, Kim HN, Kang SM, Liu JC, Lengner CJ, Otto F, Mundlos S, Stein JL, van Wijnen AJ, Lian JB, Stein GS, Choi J-Y (2008) Expression of Runx2 transcription factor in non-skeletal tissues, sperm and brain. J Cell Physiol 217: 511-517.

Jiang LS, Zhang ZM, Jiang SD, Chen WH, Dai LY (2008) Differential bone metabolism between postmenopausal women with osteoarthritis and osteoporosis. J Bone Min Res 23: 475-483.

Kanis JA, Johnell O (2011) Osteoporosis and the burden of osteoporosis-related fractures. Am J Manag Care 22: S164-S169.

Kiselak EA, Shen X, Song J, Gude DR, Wang J, Brody SL, Strauss JF, Zhang Z (2010) Transcriptional regulation of an axonemal central apparatus gene, spermassociated antigen 6, by a SRY-related high mobility group transcription factor, S-SOX5. J Biol Chem 285: 3049630505.

Komori T, Yagi H, Nomura S, Yamaguchi a, Sasaki K, Deguchi K, Shimizu Y, Bronson RT, Gao YH, Inada M, Sato M, Okamoto R, Kitamura Y, Yoshiki S, Kishimoto T (1997) Targeted disruption of Cbfa1 results in a complete lack of bone formation owing to maturational arrest of osteoblasts. Cell 89: 755-764.

Komori T(2006) Regulation of osteoblast differentiation by transcription factors. J Cell Biochem 99: 1233-1239.

Kwan Tat S, Lajeunesse D, Pelletier J-P, MartelPelletier J (2010) Targeting subchondral bone for treating osteoarthritis: what is the evidence? Best Pract Res Clin Rheumatol 24: 51-70.

Lajeunesse D (2002) Altered subchondral osteoblast cellular metabolism in osteoarthritis: cytokines, eicosanoids, and growth factors. J Musculoskelet Neuronal Interact 2: 504-506.

Lanyon LE (1984) Functional strain as a determinant for bone remodeling. Calcif Tissue Int 36 Suppl 1: S56-S61.

Lavigne P, Benderdour M, Lajeunesse D, Reboul P, Shi Q, Pelletier J-P, Martel-Pelletier J, Fernandes JC (2005) Subchondral and trabecular bone metabolism regulation in canine experimental knee osteoarthritis. Osteoarthritis Cartilage 13: 310-317.

Li B, Marshall D, Roe M, Aspden RM (1999) The electron microscope appearance of the subchondral bone plate in the human femoral head in osteoarthritis and osteoporosis. J Anat 195: 101-110.

Lian JB, Stein GS (1995) Development of the osteoblast phenotype: molecular mechanisms mediating osteoblast growth and differentiation. Iowa Orthop J 15: 118-140.

Liu F, Malaval L, Aubin JE (1997) The mature osteoblast phenotype is characterized by extensive plasticity. Exp Cell Res 232: 97-105.

Liu F, Malaval L, Gupta AK, Aubin JE (1994) Simultaneous detection of multiple bone-related mRNAs and protein expression during osteoblast differentiation: polymerase chain reaction and immunocytochemical studies at the single cell level. Dev Biol 166: 220-234. 
Liu Y, Berendsen AD, Jia S, Lotinun S, Baron R, Ferrara $\mathrm{N}$, Olsen BR (2012) Intracellular VEGF regulates the balance between osteoblast and adipocyte differentiation. J Clin Invest 122: 3101-3113.

Livak KJ, Schmittgen TD (2001) Analysis of relative gene expression data using real-time quantitative PCR and the 2(-Delta Delta C(T)) Method. Methods 25: 402-408.

Lories RJU, Luyten FP (2012) Osteoarthritis, a disease bridging development and regeneration. Bonekey Rep 1: 136.

Lowry OH, Roberts NR, Hixon WS, Elizabeth J (1954) The quantitative histochemistry of the brain : II. Enzyme measurements. J Biol Chem 207: 19-38.

Marsell R, Einhorn TA (2011) The biology of fracture healing. Injury 42: 551-555.

Massicotte F, Lajeunesse D, Benderdour M, Pelletier J-P, Hilal G, Duval N, Martel-Pelletier J (2002) Can altered production of interleukin-1beta, interleukin-6, transforming growth factor-beta and prostaglandin E(2) by isolated human subchondral osteoblasts identify two subgroups of osteoarthritic patients. Osteoarthr Cartil 10: 491-500.

McDonald RS, Gupta S, Maclean M, Ramakrishnan P, Anderson JG, MacGregor SJ, Meek RMD, Grant MH (2013) $405 \mathrm{~nm}$ Light exposure of osteoblasts and inactivation of bacterial isolates from arthroplasty patients: potential for new disinfection applications? Eur Cell Mater 25: 204-214.

Mcduffee LA, Anderson GI, Wright GM, Ryan DAJ (2006) In vitro heterogeneity of osteogenic cell populations at various equine skeletal sites Résumé Specimen collection. Can J Vet Res: 277-284.

Ninomiya JT, Tracy RP, Calore JD, Gendreau MA, Kelm RJ, Mann KG (1990) Heterogeneity of human bone. J Bone Miner Res 5: 933-938.

Nolan T, Hands RE, Bustin SA (2006) Quantification of mRNA using real-time RT-PCR 1: 1559-1582.

Oshina H, Sotome S, Yoshii T, Torigoe I, Sugata Y, Maehara H, Marukawa E, Omura K, Shinomiya K (2007) Effects of continuous dexamethasone treatment on differentiation capabilities of bone marrow-derived mesenchymal cells. Bone 41: 575-583.

Perinpanayagam H, Zaharias R, Stanford C, Brand R, Keller J, Schneider G (2001) Early cell adhesion events differ between osteoporotic and non-osteoporotic osteoblasts. J Orthop Res 19: 993-1000.

Pervaiz K, Cabezas A, Downes K, Santoni BG, Frankle MA (2013) Osteoporosis and shoulder osteoarthritis: incidence, risk factors, and surgical implications. J Shoulder Elbow Surg 22: 1-8.

Pfaffl MW (2001) A new mathematical model for relative quantification in real-time RT-PCR. Nucleic Acids Res 29: e45.

Poulet B, Ulici V, Stone TC, Pead M, Gburcik V, Constantinou E, Palmer DB, Beier F, Timmons JA, Pitsillides AA (2012) Time-series transcriptional profiling yields new perspectives on susceptibility to murine osteoarthritis. Arthritis Rheum. 64: 3256-3266.

Poulet B, De Souza R, Knights CB, Gentry C, Wilson AM, Bevan S, Chang YM, Pitsillides AA (2014) Modifications of gait as predictors of natural osteoarthritis progression in Str/Ort mice. Arthritis Rheumatol 66: 18321842.

Quarto R, Thomas D, Liang CT (1995) Bone progenitor cell deficits and the age-associated decline in bone repair capacity. Calcif Tissue Int 56: 123-129.

Rawlinson SCF, McKay IJ, Ghuman M, Wellmann C, Ryan P, Prajaneh S, Zaman G, Hughes FJ, Kingsmill VJ (2009) Adult rat bones maintain distinct regionalized expression of markers associated with their development. PLoS One 4: e8358.

Rawlinson SCF, Mosley JR, Suswillo RFL, Pitsillides AA, Lanyon LE (1995) Calvarial and limb bone cells in organ and monolayer culture do not show the same early responses to dynamic mechanical strain. J Bone Miner Res 10: $1225-1232$.

Report of a WHO study Group (1994) Assessment of fracture risk and its application to screening for postmenopausal osteoporosis. World Heal. Organ Tech Rep Ser 843: 1-129.

Richards JB, Zheng H-F, Spector TD (2012) Genetics of osteoporosis from genome-wide association studies: advances and challenges. Nat Rev Genet 13: 576-588.

Rickard DJ, Kassem M, Hefferan TE, Sarkar G, Spelsberg TC, Riggs BL (1996) Isolation and characterization of osteoblast precursor cells from human bone marrow. J Bone Miner Res 11: 312-324.

Ringner M (2008) What is principal component analysis? Nat Biotechnol 26: 303-304.

Rozen S, Skaletsky H (2000) Primer3 on the WWW for general users and for biologist programmers. Methods Mol Biol 132: 365-386.

Sanchez C, Deberg MA, Bellahcène A, Castronovo V, Msika P, Delcour JP, Crielaard JM, Henrotin YE (2008) Phenotypic characterization of osteoblasts from the sclerotic zones of osteoarthritic subchondral bone. Arthritis Rheum 58: 442-455.

Sarahrudi K, Thomas A, Braunsteiner T, WolfH, Vécsei V, Aharinejad S (2009) VEGF serum concentrations in patients with long bone fractures: a comparison between impaired and normal fracture healing. J Orthop Res 27: 1293-1297.

Saxon LK, Galea G, Meakin L, Price J, Lanyon LE (2012) Estrogen receptors alpha and beta have different gender-dependent effects on the adaptive responses to load bearing in cancellous and cortical bone. Endocrinology 153: 2254-2266.

Shah M, Kola B, Bataveljic A, Arnett TR, Viollet B, Saxon L, Korbonits M, Chenu C (2010) AMP-activated protein kinase (AMPK) activation regulates in vitro bone formation and bone mass. Bone 47: 309-319.

Shea LD, Wang D, Franceschi RT, Mooney DJ (2000) Engineered bone development from a pre-osteoblast cell line on three-dimensional scaffolds. Tissue Eng 6: 605-617.

Siggelkow H, Rebenstorff K, Kurre W, Niedhart C, Engel I, Schulz H, Atkinson MJ, Hüfner M (1999) Development of the osteoblast phenotype in primary human osteoblasts in culture: comparison with rat calvarial cells in osteoblast differentiation. J Cell Biochem 75: 2235 .

Simon DWN, Clarkin CE, Das-Gupta V, Rawlinson SCF, Emery RJ, Pitsillides AA (2008) Identifying the 
cellular basis for reimplantation failure in repair of the rotator cuff. J Bone Joint Surg Br 90: 680-684.

Sohaskey ML, Jiang Y, Zhao JJ, Mohr A, Roemer F, Harland RM (2010) Osteopotentia regulates osteoblast maturation, bone formation, and skeletal integrity in mice. J Cell Biol 189: 511-525.

Solchaga LA, Cassiède P, Caplan AI (1998) Different response to osteo-inductive agents in bone marrow- and periosteum-derived cell preparations. Acta Orthop Scand 69: 426-432.

De Souza RL, Matsuura M, Eckstein F, Rawlinson SCF, Lanyon LE, Pitsillides AA (2005) Non-invasive axial loading of mouse tibiae increases cortical bone formation and modifies trabecular organization: A new model to study cortical and cancellous compartments in a single loaded element. Bone 37: 810-818.

Tat SK, Pelletier J-P, Lajeunesse D, Fahmi H, Duval N, Martel-Pelletier J (2008) Differential modulation of RANKL isoforms by human osteoarthritic subchondral bone osteoblasts: influence of osteotropic factors. Bone 43: 284-291.

Tat SK, Pelletier J-P, Velasco CR, Padrines M, MartelPelletier J (2009) New perspective in osteoarthritis: the OPG and RANKL system as a potential therapeutic target? Keio J Med 58: 29-40.

Taylor SEB, Shah M, Orriss IR (2014) Generation of human and rodent osteoblasts. Bonekey Rep 3: 585.

Udagawa N, Takahashi N, Jimi E, Matsuzaki K, Tsurukai T, Itoh K, Nakagawa N, Yasuda H, Goto M, Tsuda E, Higashio K, Gillespie MT, Martin TJ, Suda T (1999) Osteoblasts/stromal cells stimulate osteoclast activation through expression of osteoclast differentiation factor/ RANKL but not macrophage colony-stimulating factor. Bone 25: 517-523.

Varanasi SS, Olstad OK, Swan DC, Sanderson P, Gautvik VT, Reppe S, Francis RM, Gautvik KM, Datta HK (2010) Skeletal site-related variation in human trabecular bone transcriptome and signaling. PLoS One 5: e10692.

Verstraeten A, Van Ermen H, Haghebaert G, Nijs J, Geusens P, Dequeker J (1991) Osteoarthrosis retards the development of osteoporosis. Observation of the coexistence of osteoarthrosis and osteoporosis. Clin Orthop 264: 169-177.

Vora SR, Palamakumbura AH, Mitsi M, Guo Y, Pischon N, Nugent MA, Trackman PC (2010) Lysyl oxidase propeptide inhibits FGF-2-induced signaling and proliferation of osteoblasts. J Biol Chem 285: 7384-7393.

Wade-Gueye NM, Boudiffa M, Laroche N, VandenBossche A, Fournier C, Aubin JE, Vico L, Lafage-Proust M-H, Malaval L (2010) Mice lacking bone sialoprotein (BSP) lose bone after ovariectomy and display skeletal site-specific response to intermittent PTH treatment. Endocrinology 151: 5103-5113.

Wagner W, Bork S, Horn P, Krunic D, Walenda T, Diehlmann A, Benes V, Blake J, Huber F-X, Eckstein V, Boukamp P, Ho AD (2009) Aging and replicative senescence have related effects on human stem and progenitor cells. PLoS One 4: 13.

Westacott CI, Webb GR, Warnock MG, Sims J V, Elson CJ (1997) Alteration of cartilage metabolism by cells from osteoarthritic bone. Arthritis Rheum 40: 1282-1291.
Willie BM, Birkhold AI, Razi H, Thiele T, Aido M, Kruck B, Schill A, Checa S, Main RP, Duda GN (2013) Diminished response to in vivo mechanical loading in trabecular and not cortical bone in adulthood of female $\mathrm{C} 57 \mathrm{Bl} / 6$ mice coincides with a reduction in deformation to load. Bone 55: 335-346.

Wong MM, Rao LG, Ly H, Hamilton L, Tong J, Sturtridge W, McBroom R, Aubin JE, Murray TM (1990) Long-term effects of physiologic concentrations of dexamethasone on human bone-derived cells. J Bone Miner Res 5: 803-813.

Xia L, Feng B, Wang P, Ding S, Liu Z, Zhou J, Yu R (2012) In vitro and in vivo studies of surface-structured implants for bone formation. Int J Nanomedicine 7: 48734881 .

Zhang W, Ou G, Hamrick M, Hill W, Borke J, Wenger K, Chutkan N, Yu J, Mi Q-S, Isales CM, Shi X-M (2008) Age-related changes in the osteogenic differentiation potential of mouse bone marrow stromal cells. J Bone Miner Res 23: 1118-1128.

\section{Discussion with Reviewer}

Reviewer I: If the outcome of this study is subsequently substantiated, how would this affect the use of MSCs for therapeutic applications?

Authors: It is possible that a more complete understanding of the factors governing the diversity in behaviour in osteoblasts from different types of bone, will better inform use of MSC for therapeutic applications.

It may, for instance, allow for greater "selection" of particular bone cell behaviour, favouring formation of specific bone types at a certain location, and this allow better tailoring of MSC application to the clinical, therapeutic need. Without conducting more functional studies both in vitro and in vivo it is difficult, however, to predict how this will impact on therapeutic MSC applications. Our data may be an indication that MSC from different sites will also exhibit some diversity in genetic and functional signatures, possibly owing to their particular environmental niche. This may therefore contribute to greater selection being placed on the location for MSC harvesting.

Reviewer I: What possible mechanisms do you think are involved in osteoblast diversity? Is it modified by local niches or inherent in the development pathway?

Authors: This is an interesting question. The possible mechanisms involved in osteoblast diversity are yet to be uncovered. It is possible that both local niches and inherent differences in developmental origins and pathways are involved. If we had to make a prediction, we feel that it would be likely that osteoblast diversity would reflect a combination of both local, environmental influences and inherent pre-programming. Recent evidence indicating that at least some trabecular bone osteoblasts may be derived from hypertrophic chondrocytes of the growth plate might be interpreted as evidence that such diversity in osteoblast origins indeed exists (Yang L et al., 2014; Yang G et al., 2014; Zhou et al., 2014). Without definitive identification 
of the mechanisms and factors governing such diversity, however, it is not possible to pinpoint the answer to this fascinating question.

Reviewer II: Do the authors think that these findings would be the same in large species (ovine/bovine), small rodent species (mouse/guinea pig/rat) and in non-mammalian species?

Authors: We acknowledge that the impact of the differing human bone type-related cell attributes reported here would be modified if they were conserved in all species. Selection of both location for sampling and species would however need to be made carefully. Bone size would need to be taken into account, as obtaining sufficiently large samples from very small 1 rodents is not trivial. Rodent bone might also be deemed inappropriate for comparison, as it is predominantly primary rather than secondary. Larger species do not necessarily simplify this choice, as bone from ovine and bovine species, although macroscopically similar to human, can have plexiform structure, with combinations of woven/lamellar organisation sandwiching vascular plexuses (Aerssens et al., 1997; Manilay et al., 2013; Pearce et al., 2007). Different species also exhibit divergent post-natal growth, modelling and remodelling patterns and this might also translate to differences in osteoblast in vitro. It is nonetheless pertinent to visit how any such studies might be interpreted too. Would failure to replicate our findings in all species necessarily diminish their significance to human? Would their replication in all species offer any explanation regarding their origins? Do/ how do bone type-related differences in cell behaviour impact on physiological bone responses in vivo? Can they be exploited to achieve targeting of one bone site over another? There are many further questions that our findings raise and whether there are similarities (or differences) in osteoblasts isolated from similar bone types in other mammalian and non-mammalian species would be of great interest in this regard.

\section{Additional References}

Manilay Z, Novitskaya E., Sadovnikov E, McKittrick J (2013) A comparative study of young and mature bovine cortical bone. Acta Biomater. 9: 5280-5288.

Pearce AI, Richards RG, Milz S, Schneider E, Pearce SG (2007) Animal models for implant biomaterial research in bone: A review. Eur Cell Mater 13: 1-10.

Yang G, Zhu L, Hou N, Lan Y, Wu YM, Zhou B, Teng Y, Yang X (2014). Osteogenic fate of hypertrophic chondrocytes. Cell Res 24: 1266-1269.

Yang L, Tsang KY, Tang HC, Chan D, Cheah KS (2014). Hypertrophic chondrocytes can become osteoblasts and osteocytes in endochondral bone formation. Proc Natl Acad Sci U S A 111: 12097-12102.

Zhou X, von der Mark K, Henry S, Norton W, Adams H, de Crombrugghe B (2014) Chondrocytes transdifferentiate into osteoblasts in endochondral bone during development, postnatal growth and fracture healing in mice. PLoS Genet 10: e1004820. 